\title{
OPEN The time course of molecular acclimation to seawater in a euryhaline fish
}

\author{
Lucrezia C. Bonzi $^{1 凶}$, Alison A. Monroe ${ }^{1}$, Robert Lehmann $^{2}$, Michael L. Berumen ${ }^{1}$, \\ Timothy Ravasi ${ }^{3,4}$ \& Celia Schunter ${ }^{5 凶}$
}

The Arabian pupfish, Aphanius dispar, is a euryhaline fish inhabiting both inland nearly-freshwater desert ponds and highly saline Red Sea coastal lagoons of the Arabian Peninsula. Desert ponds and coastal lagoons, located respectively upstream and at the mouths of dry riverbeds ("wadies"), have been found to potentially become connected during periods of intense rainfall, which could allow the fish to migrate between these different habitats. Flash floods would therefore flush Arabian pupfish out to sea, requiring a rapid acclimation to a greater than $40 \mathrm{ppt}$ change in salinity. To investigate the molecular pathways of salinity acclimation during such events, a Red Sea coastal lagoon and a desert pond population were sampled, with the latter exposed to a rapid increase in water salinity. Changes in branchial gene expression were investigated via genome-wide transcriptome measurements over time from $6 \mathrm{~h}$ to 21 days. The two natural populations displayed basal differences in genes related to ion transport, osmoregulation and immune system functions. These mechanisms were also differentially regulated in seawater transferred fish, revealing their crucial role in long-term adaptation. Other processes were only transiently activated shortly after the salinity exposure, including cellular stress response mechanisms, such as molecular chaperone synthesis and apoptosis. Tissue remodelling processes were also identified as transient, but took place later in the timeline, suggesting their importance to long-term acclimation as they likely equip the fish with lasting adaptations to their new environment. The alterations in branchial functional pathways displayed by Arabian pupfish in response to salinity increases are diverse. These reveal a large toolkit of molecular processes important for adaptation to hyperosmolarity that allow for successful colonization to a wide variety of different habitats.

Salinity is one of the main abiotic factors shaping the distribution and habitat preference of fish and other aquatic taxa. Teleosts have evolved different strategies to maintain osmotic homeostasis depending on water ion concentrations. In seawater, fish drink copiously to combat water lost via osmosis, concurrently suffering passive intake of high quantities of salts. Specialized mitochondria-rich cells of the gill epithelium, called ionocytes, are then responsible for active excess ion secretion ${ }^{1,2}$. In freshwater, fish face ion loss and passive osmotic water intake. To compensate for the consequent dilution of their body fluids, they actively uptake ions from the surrounding medium through specialized ionocytes ${ }^{1,2}$. Given the profound differences in osmoregulatory mechanisms in fresh versus seawater, changes in salinity represent a significant challenge for fish, and the induced osmotic stress can interfere with physiological homeostasis and impairment of biological processes ${ }^{3}$. As a consequence, most teleost fishes are restricted to limited habitat salinities (stenohaline fish). Other species, termed euryhaline fish, have evolved osmoregulatory plasticity in the organs involved in maintenance of osmotic balance ${ }^{4}$. In particular plastic modifications to the gill epithelium, the main tissue responsible for osmoregulation in fish ${ }^{2}$, grant the ability to live in wider salinity ranges and exploit larger habitat diversity.

\footnotetext{
${ }^{1}$ Red Sea Research Center, Biological and Environmental Science and Engineering Division, King Abdullah University of Science and Technology, Thuwal, Saudi Arabia. ${ }^{2}$ Biological and Environmental Sciences and Engineering Division, Computer, Electrical and Mathematical Sciences and Engineering Division, King Abdullah University of Science and Technology, Thuwal, Saudi Arabia. ${ }^{3}$ Marine Climate Change Unit, Okinawa Institute of Science and Technology Graduate University, 1919-1 Tancha, Onna-son, Okinawa, Japan. ${ }^{4}$ Australian Research Council Centre of Excellence for Coral Reef Studies, James Cook University, Townsville, QLD, Australia. ${ }^{5}$ Swire Institute of Marine Science, School of Biological Sciences, The University of Hong Kong, Pokfulam Road, Hong Kong SAR, China. ${ }^{\circledR}$ email: lucrezia.bonzi@gmail.com; celiaschunter@gmail.com
} 
Extensive work has been performed to understand the molecular underpinnings responsible for gill plasticity in euryhaline species. Early studies focused on salinity-driven expression changes of specific ion transporters and osmoregulatory genes ${ }^{5-7}$, expanding the existing knowledge regarding branchial ion secretion and absorption mechanisms. In particular, the role of $\mathrm{Na}^{+} / \mathrm{K}^{+}$-ATPase (NKA), $\mathrm{Na}^{+} / \mathrm{K}^{+} / \mathrm{Cl}^{-}$transporter (NKCC1), and cystic fibrosis transmembrane conductance regulator (CFTR) in marine-type ion-extruder ionocytes was extensively investigated, and found to be highly conserved in seawater adapted teleosts ${ }^{1,2}$. In contrast, the mechanisms for ion absorption were found to be quite diverse across different species, and several ionocyte subtypes have been described in freshwater adapted fishes ${ }^{8-11}$. Advancements in molecular and sequencing technologies have led to the discovery of additional essential pathways for osmoregulation in euryhaline fish. Transcriptomics has provided the means to identify genes and pathways involved in osmosensing and activation of signalling cascades that initiate the osmotic stress response and the acclimation processes ${ }^{12-15}$. Profound gill remodelling, observed by microscopy and immunocytochemistry studies as alterations in ionocyte morphology and abundance ${ }^{16-18}$, was linked to salinity-specific ion transporter and protein de novo synthesis or relocation inside the cell, activation of apoptosis pathways, and modifications of the cytoskeleton, cell-cell junctions, and the extracellular matrix ${ }^{19-22}$. Euryhaline fish are therefore able to switch between hypo- and hyper-osmoregulation when confronted with changes in environmental salinity, although rapid increases in intra- and extra-cellular ion concentrations can negatively affect structural and functional properties of tissue macromolecules, such as proteins, lipids and $\mathrm{DNA}^{23,24}$. Markers for an evolutionarily conserved cellular stress response (CSR) triggered by macromolecular damage have been identified in gene expression and transcriptomic studies in fish exposed to changes in salinity ${ }^{25-27}$. The CSR is comprised of defence mechanisms to protect cellular components, including the expression of molecular chaperones, and to re-establish homeostasis, by accumulation of organic compatible osmolytes and osmoregulatory mechanism switch. Moreover, the replication of damaged DNA is prevented through transcription inhibition, apoptosis and cell cycle arrest ${ }^{23,24,28}$. The processes of osmotic stress response, ion homeostasis restoration and tissue remodelling are energetically demanding for euryhaline fish ${ }^{23,29,30}$, and differential regulation of metabolic and mitochondrial respiration pathways during salinity challenges have been reported in several studies ${ }^{12,27,31,32}$. Given the large percentages of their energy budget consumed in response to osmotic stress, compromises in the allocation of energetic resources have been hypothesized, and consequent impairments in physiological processes such as development, growth and immune response have been reported ${ }^{15,33-35}$. While a variety of processes involved in osmotic stress and salinity acclimation in teleosts have been defined, their ecological adaptive potential in natural colonization events is still not clear, especially the exact timing of stress, acclimation and adaptation responses and mechanisms. A number of time series salinity acclimation studies have been performed ${ }^{5,12,15,27,36,37}$, using designated single gene or microarray expression analyses. However, RNAseq whole-genome transcriptomics combined with an appropriate model species and collection time point selection would allow for the capture of a more complete picture of both the temporal and the mechanistic aspects of the branchial salinity response in euryhaline fish during highly saline habitat colonization.

The Arabian pupfish, Aphanius dispar (Rüppell, 1829), is a euryhaline species member of the Cyprinodontidae family with widespread habitat ranges ${ }^{38}$. Its distribution encompasses areas around the Red Sea, the Persian Gulf, the Arabian Sea, and part of the south-eastern Mediterranean basin, with populations living from inland freshwater reservoirs to coastal lagoons, and hot sulphuric springs. Along the western coast of Saudi Arabia, the Arabian pupfish is found in a large variety of environmental salinities, ranging from highly saline (41-44 ppt) Red Sea coastal lagoons to nearly-freshwater desert oases $(0.7-1.5 \mathrm{ppt})$ with no permanent connection to the sea. In a recent study ${ }^{39}$, genetic connectivity analyses indicated clustering by geographic distance rather than ecotype, despite the large environmental differences of the locations. As supported by hydrological mapping of the region, pupfish may rely on periods of intense rainfall to colonize these extremely different habitats when they become temporarily hydrologically connected. The importance of ephemeral surface water in conditioning desert fish connectivity has already been established in other arid environments ${ }^{40-42}$. In the Lake Eyre basin in Australia, the desert goby Chlamydogobius eremius relies on temporary surface waters and flood-driven dispersal for extensive gene flow across large distances and different habitats ${ }^{43}$. Similarly, in the desertic areas of Arizona, flash floods have been proved to cause longitudinal displacement of fish from pools to downstream locations ${ }^{44,45}$. Such a hypothesis would imply that during floods Arabian pupfish might be either abruptly flushed out from the desert ponds to the marine environment, and/or vice versa migrate upstream from the coastal lagoons, requiring considerable acclimation capacities in order to survive such a rapid and drastic change in salinity. While salinity changes have been observed to influence Arabian pupfish osmotic pressure, body ion content, and gill permeability ${ }^{46,47}$, no differences in performance indicators, such as resting metabolic rate, swimming speed and activity level, were caused by up to $70 \mathrm{ppt}$ increases in water salinity ${ }^{48}$. For these reasons, the Arabian pupfish represents an excellent system to investigate the mechanisms underlying the plasticity of euryhaline fish gills during salt stress events, and the processes that allow them to acclimate long-term and colonize novel habitats. In this study, nearly-freshwater adapted Arabian pupfish from inland desert ponds were transferred to highly saline water to mimic a potential colonization event. The acclimation course was explored over time to disentangle the short-term processes responding to acute osmotic stress from the strategies providing the fish with longer-term adjustments required for prolonged adaptation in seawater environments.

\section{Materials and methods}

Experimental design. To evaluate the natural acclimation of Arabian pupfish from near-freshwater to a large increase in salinity over a short period of time, adult Aphanius dispar from the same genetic unit ${ }^{39}$ were $^{2}$ collected using a seine net from two Saudi Arabian sites, including a near-freshwater (1.45 ppt) desert pond and a highly saline Red Sea coastal lagoon (43.49 ppt; Suppl. Table 1) between November 2015 and January 2016 (Fig. 1). 
a Map of Saudi Arabia

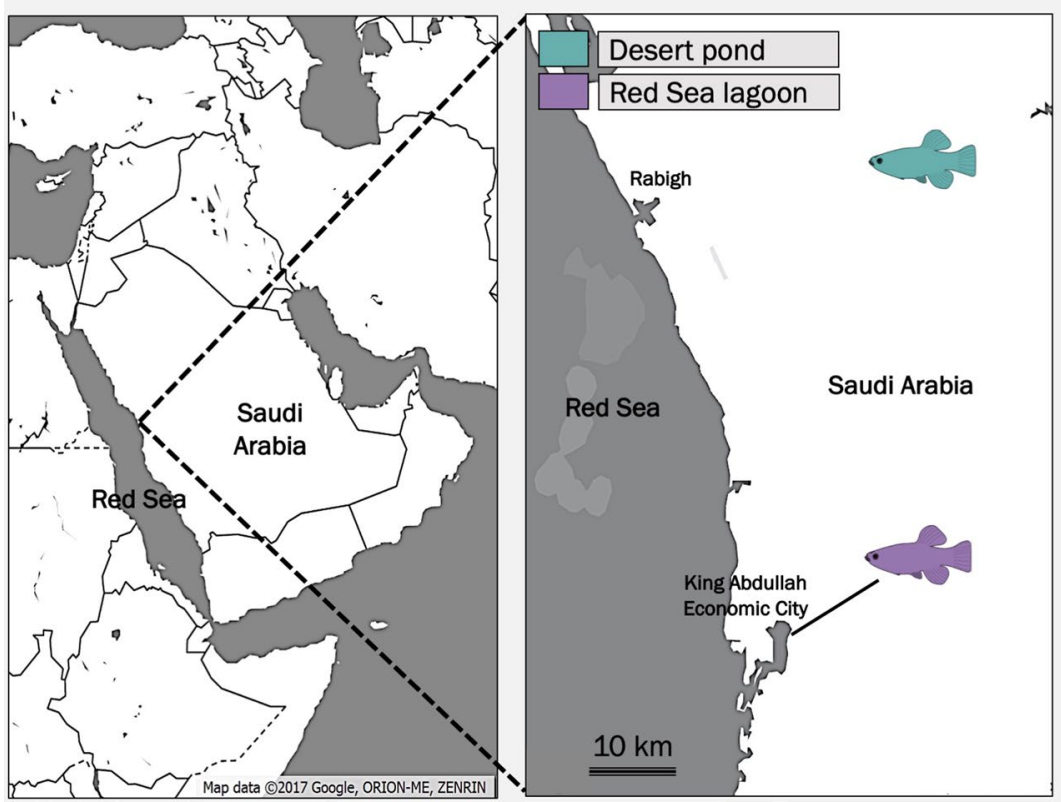

c Pictures of sample sites
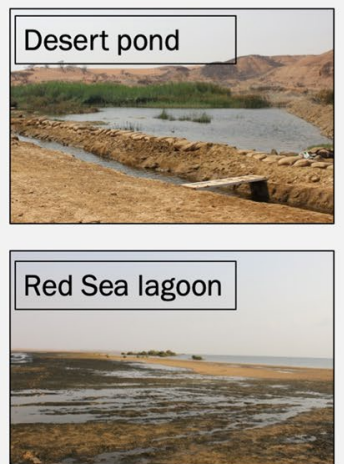

d Pictures of Arabian pupfish

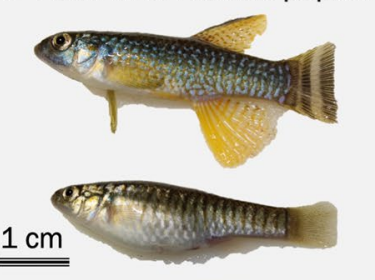

Figure 1. Sampling locations and target organism. (a) Map of the region with inset (b) showing the specific sampling locations in the central western region of Saudi Arabia. (c) Photos of the sampling sites. (d) Pictures of collected male (top) and female (bottom) Arabian pupfish.
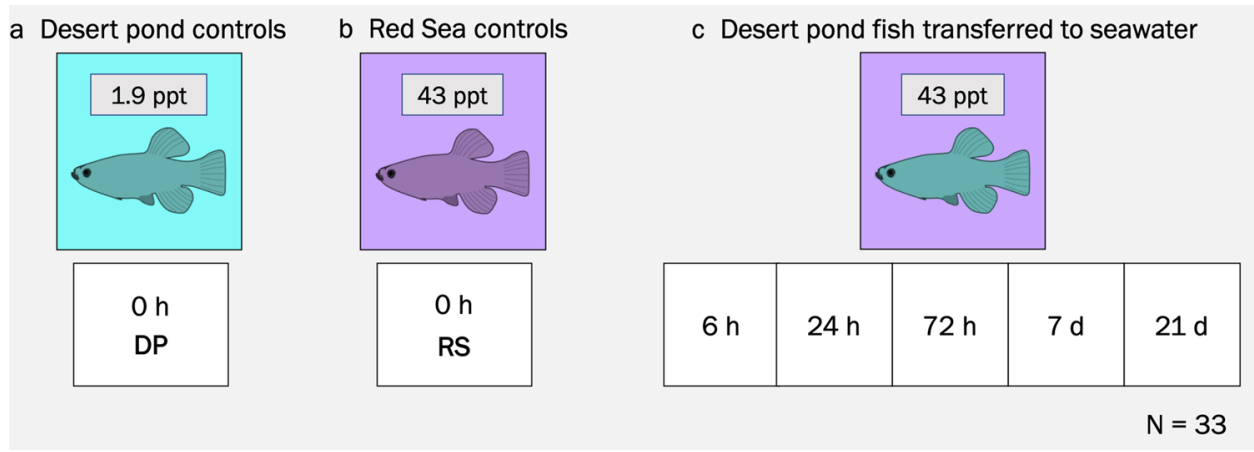

Figure 2. Experimental design. (a) Fish from desert pond (DP) kept in native water salinity (1.9 ppt) were sampled at time 0 . (b) Fish from Red Sea lagoon (RS) kept in native water salinity (43 ppt) were sampled at time 0 . (c) Fish from desert pond transferred to seawater $(43 \mathrm{ppt})$ were sampled at 5 different time points. A total of 33 samples were analyzed.

The fish were transported to the King Abdullah University of Science and Technology (KAUST) Coastal and Marine Resources Core Lab and maintained in closed-system tanks. The conditions in the aquaria resembled those of the collection sites with $8.32 \pm 0.03 \mathrm{pH}, 10 \mathrm{~L}: 14 \mathrm{D}$ photoperiod, and salinity at $1.92 \mathrm{ppt} \pm 0.01$ SE for the desert pond fish and $42.68 \mathrm{ppt} \pm 0.09 \mathrm{SE}$ for the coastal lagoon fish (Suppl. Table 2). Salinity was achieved using seawater, diluted for the desert pond fish with dechlorinated tap water. In order to avoid potential confounding effects due to temperature differences, tank water was kept at $26^{\circ} \mathrm{C}$, an intermediate value between the two collection site ones $\left(31.6^{\circ} \mathrm{C}\right.$ desert pond; $20.9^{\circ} \mathrm{C}$ coastal lagoon). Fish were acclimated to such holding conditions for more than eight months before the salinity change experiment. All fish were kept at low densities, with maximum seven individuals per $80 \mathrm{~L}$ tank, in six replicate tanks per treatment, and fed once a day ad libitum with commercial pelleted feed. In October 2016, the osmotic challenge experiment started: fish from the desert pond population were directly transferred to seawater, in order to mimic the change in salinity they might experience during potential colonization of coastal lagoons of the Red Sea (Fig. 2). Temperature, photoperiod and $\mathrm{pH}$ were kept constant during the entire duration of the experiment in order to avoid any confounding effects. No mortality was recorded throughout the whole experiment. Fish were sampled pretransfer $(0 \mathrm{~h})$ from both populations (1.9 ppt and $43 \mathrm{ppt}$ ), and at five post-transfer time points ( $43 \mathrm{ppt} ; 6 \mathrm{~h}, 24 \mathrm{~h}, 72 \mathrm{~h}, 7$ days, 21 days), always at the same time of the day to avoid potential confounding effects (except for the $6 \mathrm{~h}$ time point). At each sampling event, fish from different replicate tank were rapidly euthanized using an overdose of tricaine methanesulphonate 
(MS-222, MP Biomedicals), sexed, and length was measured (Suppl. Table 3). For each individual, the right gill basket was excised and snap-frozen in liquid nitrogen and stored at $-800{ }^{\circ} \mathrm{C}$ for subsequent RNA extraction. All procedures were performed in accordance with relevant guidelines and were conducted under KAUST Institutional Biosafety and BioEthics Committee's ethics approval 15IBEC35_Ravasi.

RNA-sequencing. RNA was isolated from gill samples using a Qiagen AllPrep DNA/RNA mini kit, following homogenization in RLT Plus buffer with MP Biomedicals FastPrep-24 homogenizer, and DNase I treated (RNase-Free DNase Set, Qiagen). Sample quality was checked using a TapeStation RNA ScreenTape assay (Agilent), and samples with low RNA quality/quantity standards (RIN $<3.3$ or $<2.5 \mu \mathrm{g}$ ) and/or that showed degradation on the electropherogram profile were not processed further. For this reason, final sample numbers per time point varied between three and six for a total of 33 samples (Suppl. Table 3). Libraries for paired-end fragments were prepared using the Illumina TruSeq stranded mRNA Library Preparation Kit, according to the manufacturer's protocol, with each sample uniquely barcoded. Quality control check and quantification were performed with a Bioanalyzer High Sensitivity DNA assay (Agilent). Three library pools were run on an Illumina HiSeq 4000 by the King Abdullah University of Science and Technology Bioscience Core Lab.

Transcriptome assembly. Raw reads were processed for quality trimming and adapter removal with Trimmomatic v0.36 ${ }^{49}$, using ILLUMINACLIP:2:30:10 HEADCROP:10 SLIDINGWINDOW:4:20 MINLEN:70, and inspected with FastQC ${ }^{50}$ before and after quality filtering. Trimmed reads were later corrected from random sequencing errors using a $k$-mer based method, Rcorrector ${ }^{51}$. Unfixable reads were discarded. Trimmed and corrected reads from all samples (Suppl. Table 3) were used to de novo assemble the A. dispar gill transcriptome using Trinity v2.4. $0^{52}$ with default settings. The assembly was then decontaminated using a hierarchical clustering algorithm called Model-based Categorical Sequence Clustering (MCSC) ${ }^{53}$. The MCSC pipeline was tested at five different clustering levels to determine the best one (level 3, based on the highest SS ratio), and the superclass Actinopterygii was chosen for the white list ratio calculation. Putative coding regions were predicted by TransDecoder v5.5. $0^{54}$, and integrated with homology search against the Pfam protein domain database using HMMER v3.2.15, and the UniRef90 protein database using blastp (BLAST + v2.6.0) $)^{56}$, e value $\leq 1 \mathrm{e}^{-5}$. The decontaminated assembly was then filtered based on TransDecoder results, retaining only the single best open reading frame (ORF) per transcript. Sequence redundancy was reduced using cd-hit-est from the CD-HIT v4.8.1 package $^{57}$ with $95 \%$ identity as clustering threshold. At each filtering stage, the quality of the assembly was evaluated by checking the basic alignment summary metrics, as well as quantifying the read representation by mapping the cleaned reads back to the transcriptome with Bowtie2 v2.3.4.1 ${ }^{58}$. Moreover, to evaluate the completeness of the assembly, and to control for potential loss of core genes during the filtering process, BUSCO v3.0 $2^{59}$ was run after every filtering step, using the provided Actinopterygii set of 4584 Benchmarking Universal Single-Copy Orthologs.

Annotation, differential gene expression and gene ontology analysis. Transcriptome annotation was performed first by BLAST searches of the TransDecoder predicted ORFs and the untranslated transcripts, using blastp and blastx algorithms respectively (evalue $\leq 1 \mathrm{e}^{-5}$ ), against the UniProtKb and the NCBI non-redundant (nr) databases. Where conflicts were found, the following order of priority was observed: UniProtKb/SwissProt, NCBI nr, and UniProtKb/TrEMBL. BLAST results were then loaded in OmicsBox v1.4.11 ${ }^{60}$, where Gene Ontology (GO), InterPro, and EggNOG ${ }^{61}$ annotations were additionally performed using Blast $2 \mathrm{GO}^{62}$.

To test for gene differential expression (DE) between the two source populations, as well as along the salinity acclimation time series, reads from each sample were first quantified using Salmon v1.1.0 $0^{63}$ in mapping-based mode against the de novo assembled transcriptome. Transcript abundance estimates were then summarized at gene level and imported in DESeq2 v1.26.0 $0^{64}$ using the package tximport v1.14.2 ${ }^{65}$ in R v3.6.1. To visually check for possible overall patterns, outliers and batch effects, raw counts were transformed using the $v s t$ function from DESeq2 package, and principal component analyses (PCAs) were run on the 500 most variable genes across samples using plotPCA function of the same package. Ellipses were drawn using ggplot2 stat_ellipse function in R. Based on PCA results and Cook's distances calculated by the DESeq function, three samples (DP_Rep1, 24h_Rep4, 21d_Rep5) were labelled as outliers and excluded from the DE analysis. Differentially expressed genes (DEGs) were identified from the remaining 30 samples (3-6 samples/time-point) running pairwise comparisons of control populations and post-transfer time points using the contrast function of DESeq2 with shrunken log2 Fold Change $(\log 2 \mathrm{FC})$ estimates by apeglm ${ }^{66}$. The threshold cut-offs chosen to identify significant DEGs were $|\log 2 \mathrm{FC}| \geq 1$, False Discovery Rate (FDR) adjusted $p$-value ${ }^{67}<0.05$ (Wald test), and a mean expression of $>10$ reads (baseMean), as similarly done in other studies on osmotic responses in fish ${ }^{68-70}$.

To identify groups of genes showing comparable trends, such as rapid or longer-term responses to the salinity challenge, DEGs revealing similar expression patterns across time points were clustered. Additionally, ImpulseDE2 v1.10.0 ${ }^{71}$, a Bioconductor R package specifically designed for time series data, was employed in case-only mode to discern steadily increasing or decreasing expression trajectories from transiently up- or down-regulated genes (FDR adjusted $p$-value ${ }^{67}<0.05$ ). For all clustering purposes, Red Sea population samples were treated as if they belonged to an additional time-point, the last in the acclimation timeline (long-term acclimation beyond 3 weeks).

Functional enrichment analyses were performed in OmicsBox v1.4.11 ${ }^{60}$, with the Fisher's Exact Test $($ FDR $<0.05)$ after removing duplicated annotations from the differentially expressed genes (DEGs) and identified gene cluster sets to find over-represented GO terms between controls and post-transfer time points. 


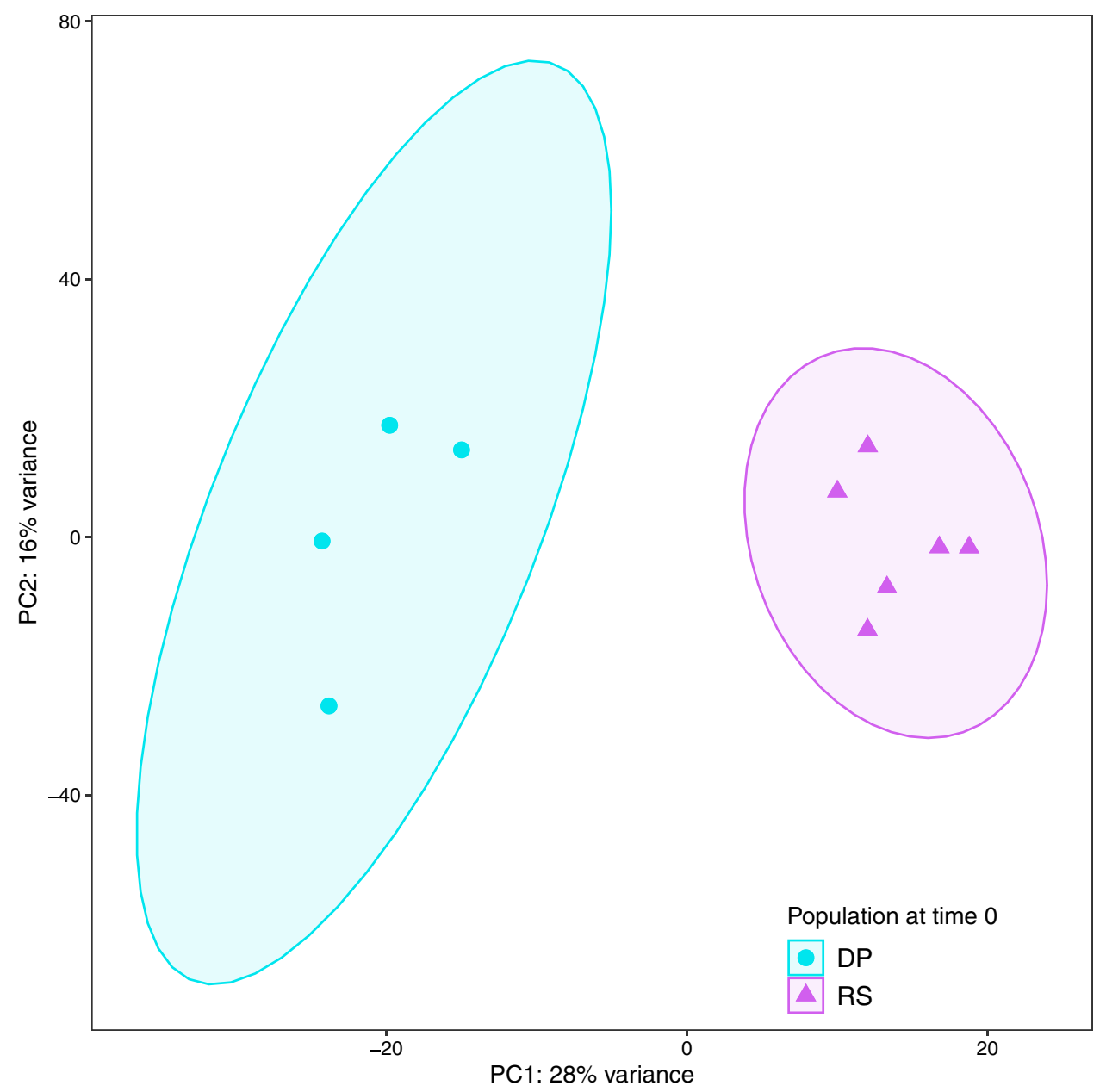

Figure 3. Principal component analysis (PCA) of variance stabilized expression values of the 500 most variable genes for the gills of desert pond $(n=4)$ and Red Sea coastal lagoon $(n=6)$ Aphanius dispar individuals at time 0. $44 \%$ of the total variation is explained by the first two components.

\section{Results}

Transcriptome assembly and annotation. The first de novo transcriptome assembly for Aphanius dispar was created from a total of 1.38 billion raw reads with an average of 24.5 million reads per sample after trimming and error correction steps (Suppl. Table 3). These high-quality reads were used to de novo assemble the Arabian pupfish gill transcriptome, which resulted in 650,824 contigs with a $97.2 \%$ overall mapping rate, an N50 of $1275 \mathrm{bp}$, and $86.2 \%$ BUSCO completeness score using the Actinopterygii database (Suppl. Table 4). A total of $2.9 \%$ of contigs were filtered out in the decontamination step, and among the remaining $631,806,141,428$ contigs were predicted to contain a coding region. The final redundancy reduced transcriptome resulted in 99,167 contigs of N50 2302 bp, E90N50 2519 bp, with an average of 75.0\% mapping rate and 86.1\% of complete BUSCO genes. Tximport gene-level summarization of the final transcriptome yielded 55,451 genes. 36,863 of these genes (66.5\%) were successfully annotated using SwissProt database, and another 11,078 genes had hits in the NCBI nr database. 446 more genes had positive blast hits when searched against TrEMBL, for a combined total of 48,337 annotated genes $(87.2 \%)$.

Gene expression differences in natural populations. The two sampled populations, desert pond (DP) and the highly saline Red Sea (RS) coastal lagoon, exhibited a clear branchial gene expression separation even after months of acclimation to the same holding conditions, salinity excluded (time 0; Fig. 3). Such differences in gene expression were partly conserved throughout the salinity challenge (Suppl. Fig. 1). The pairwise comparison of fish in their original salinities resulted in 552 differentially expressed genes (DEGs; Suppl. Table 5), which is the largest expression difference of the experiment (Fig. 4). Several functions were differentially regulated in the two populations, in particular ion transport and immune system. Full names for gene symbols can be found in Suppl. Table 6.

Ion transport related terms represented $70 \%$ of total enriched GO categories between the populations at time 0 (Suppl. Table 7). The RS individuals in particular upregulated specific seawater ion transporters, such as the $\mathrm{Na}^{+} / \mathrm{K}^{+} / \mathrm{Cl}^{-}$transporter (SLC12A2), the cystic fibrosis transmembrane conductance regulator (CFTR), and the transient receptor potential (TRP) cation channel subfamily V member 1 (TRPV1), together with genes 


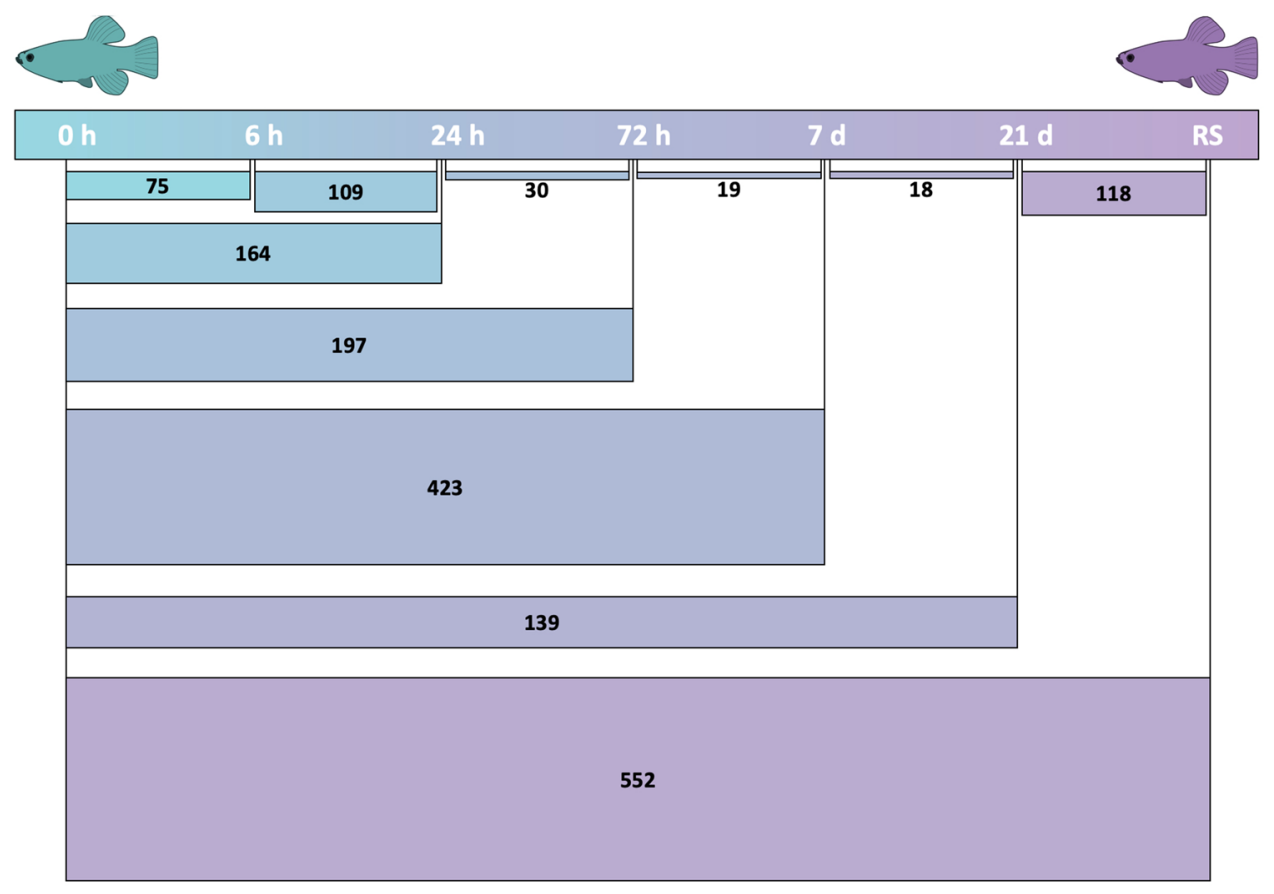

Figure 4. Numbers of differentially expressed genes in pairwise comparisons of desert pond fish controls $(0 \mathrm{~h})$ versus seawater exposed fish at different time points ( 6 h, 24 h, 72 h, 7 d, $21 \mathrm{~d})$ and Red Sea (RS) population, and consecutive post-transfer time points.

involved in their regulation, such as serine/threonine kinase 39 (STK39) and the WNK lysine deficient protein kinase 2 (WNK2). Similarly upregulated in the RS population were other ion transporters and genes important in osmoregulation such as potassium channels and their modulators (KCNN3, KCNJ1, KCNJ15, ABCC8), voltage-gated calcium channel subunits (CACNA1H, CACNA1S), ammonium transporters Rh (RHAG, RHCG), sodium/hydrogen exchangers and regulators (NHEB, SLC9A2, SLC9A3R2), as well as inositol monophosphatase 1 (IMPA1) and vasoactive intestinal peptide receptor (VIPR1). Several $\mathrm{Na}^{+} / \mathrm{K}^{+}$-transporting ATPase (NKA) subunits (ATP1A1, ATP1A3) were also differentially expressed between the two populations, and elevated expression in the nearly-freshwater DP fish was found for a different set of ion channels, including members of the transient receptor potential (TRP) cation channel superfamily (TRPM2, TRPM5, TRPM7, TRPV4), chloride channels like the chloride channel protein 2 (CLCN2), the inward rectifier potassium channel 2 (KCNJ2), and the intracellular channel inositol 1,4,5-trisphosphate receptor type 1 (ITPR1), together with its modulator, the calcium binding protein 1 (CABP1). Aquaporin 3 (AQP3) was also upregulated in DP samples.

The two populations also showed differential regulation of the immune system. $\mathrm{C}-\mathrm{C}$ motif chemokine ligands 3 and 25 (CCL3, CCL25) were upregulated in the RS population, while members of the C-X-C motif chemokine family (CXCL8, CXCL11.6, CXCL14) were upregulated in the DP fish, enriching the "chemokine activity" function. Moreover, C-C chemokine receptors (CCR4, CCR6) were upregulated in the gills of the DP population, while several genes coding for components of acquired immunity were upregulated in the seawater RS individuals, like immunoglobulins and major histocompatibility complex proteins (IGKC, IGHM, IGL1, IGKV4-1, MR1, H2-EA).

A few other functions were divergent between the populations, such as polyamine metabolism, whose related genes (ODC1, ARG1, PAOX) were upregulated in DP. Two functions were exclusive to the RS population: O-linked glycosylation, represented by five upregulated genes (B3GNT7, ST3GAL1, ST3GAL2, ST6GALNAC2, ST8SIA6), and keratinization, with the upregulation of cornifelin (CNFN), envoplakin (EVPL), keratins (XK70A, $\mathrm{K} 1 \mathrm{C} 1$ ), and transglutaminase 5 (TGM5).

Time course of the molecular responses to the salinity challenge. The selected experimental timeline and the clustering analyses of differentially expressed genes along the acclimation window (Fig. 4) allowed for the discovery of distinctively timed processes in the Arabian pupfish branchial response to the abrupt increase in salinity. While some DEGs were only transiently differentially regulated along the acclimation timeline (Fig. 5a), 231 and 269 genes steadily increased or decreased, respectively (Fig. 5b; Suppl. Table 8), and in particular the downregulated genes exhibited enrichment in cell cycle related terms (Suppl. Table 9). Through the investigation of each time point, mechanisms typical of a short-term stress response were uncovered at 6 and $24 \mathrm{~h}$ post-transfer, while the $72 \mathrm{~h}$ and 7 day time points revealed cell cycle arrest and tissue remodelling events, and the last time point ( 21 days post-transfer) was characterized by longer-term acclimation processes, many resembling the Red Sea population transcriptional profile (Fig. 6). 
a Transiently differentially regulated genes over the timeline

I

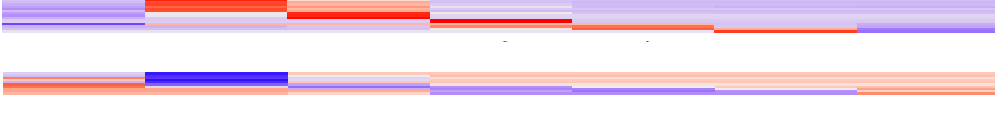

b Monotonously differentially regulated genes over the timeline

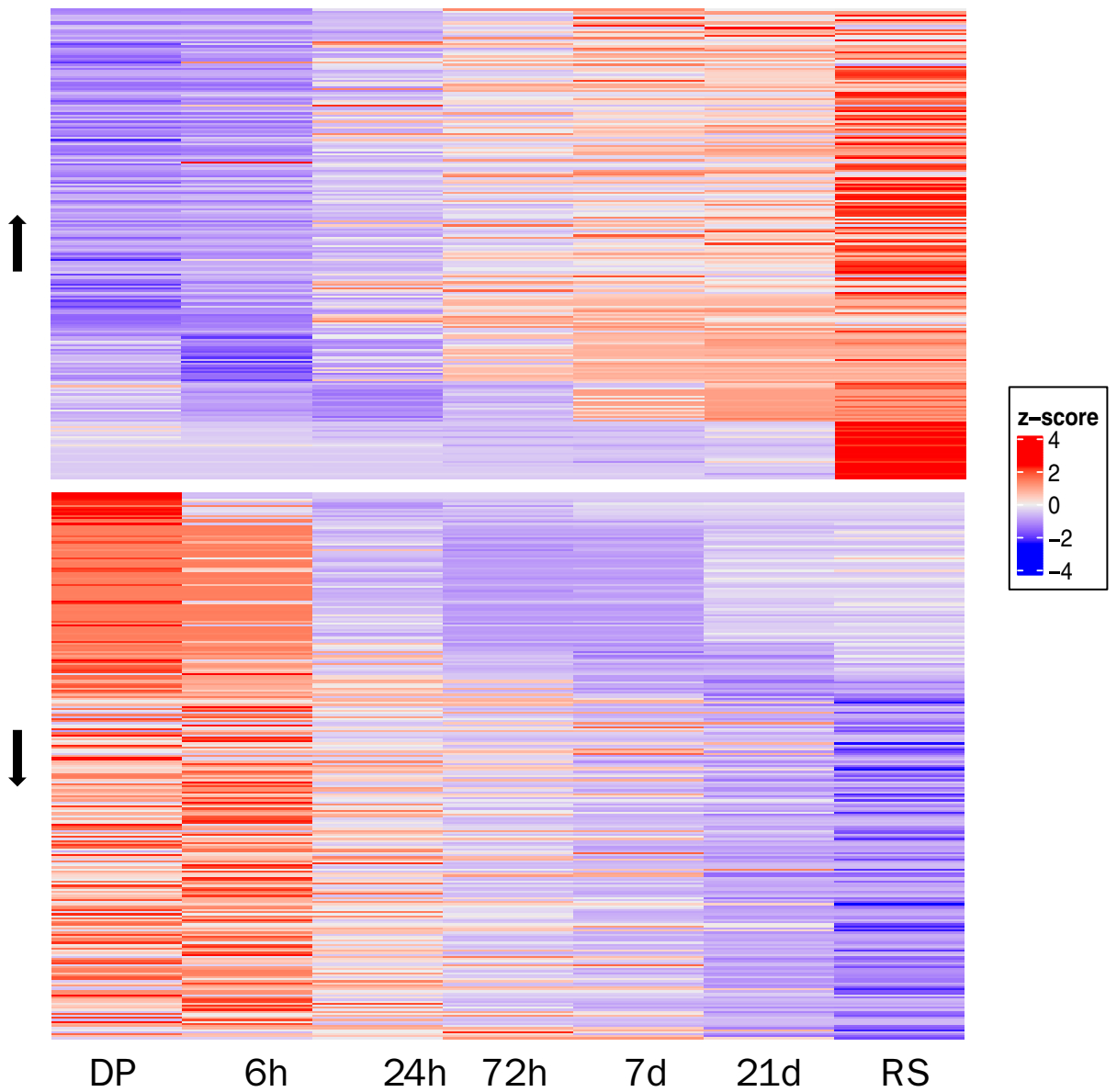

Figure 5. Heatmap of transiently (a) or monotonously (b) up- $(\uparrow)$ and down- $(\downarrow)$ regulated differentially expressed genes (FDR corrected $p$-value $<0.05$ ) over the experimental timeline, as identified by ImpulseDE2 analysis. DP and RS stand for desert pond and Red Sea samples, respectively.

Just six hours after the start of the hyperosmotic challenge, 75 branchial genes showed a statistically significant change in expression compared to pre-transfer controls (Suppl. Table 10). This immediate reaction was based on a wide array of different functions (Suppl. Table 11). The acute osmotic stress caused the onset of cell signalling cascades, with the differential expression of prolactin receptor (PRLR), the stress responsive hydroxysteroid 11-beta dehydrogenase 2 (HSD11B2), which modulates intracellular cortisol levels, and serum/glucocorticoid regulated kinase 1 (SGK1), important in the cellular stress and DNA damage responses. Furthermore, the osmotic stress response was found to entail ion homeostasis pathways, through the regulation of ion transport and ion channel activity (CFTR, KCNJ2, TCAF, WNK2), and organic osmolyte synthesis and transport (GLUL, IMPA1, ISYNA1-B, SLC6A20, SLC5A7, ABCG20). In particular, ISYNA1-B was transiently upregulated between 6 and $24 \mathrm{~h}$ and, in the same interval, IMPA1 showed very high levels of expression, while being upregulated across the whole timeline (Suppl. Fig. 2a). Another important function found at $6 \mathrm{~h}$ post-transfer was tissue modification, by means of cellular proliferation and differentiation (GPM6B, NR4A3, NHSL1), and keratinization (CNFN, DSC1). Genes involved in the immune response were also differentially expressed at $6 \mathrm{~h}$, and class I histocompatibility antigen, F10 alpha chain (HA1F) was upregulated post-transfer. Upregulation of genes implicated in lipid (ALOXE3, ALOX15B, CPT1A) and glucose (GAD1, SLC2A8) metabolism and transport was also found. Although a few DEGs were found to be related to circadian rhythm processes (NFIL3, NR1D1, NR1D2, PER2), this result is most likely due to the sampling time occurring at a different moment of the day, rather than an effect of the salinity change. For the same reason, the possibility that other DEGs in this time point might be responding to the difference in time of day rather than salinity cannot be excluded. 


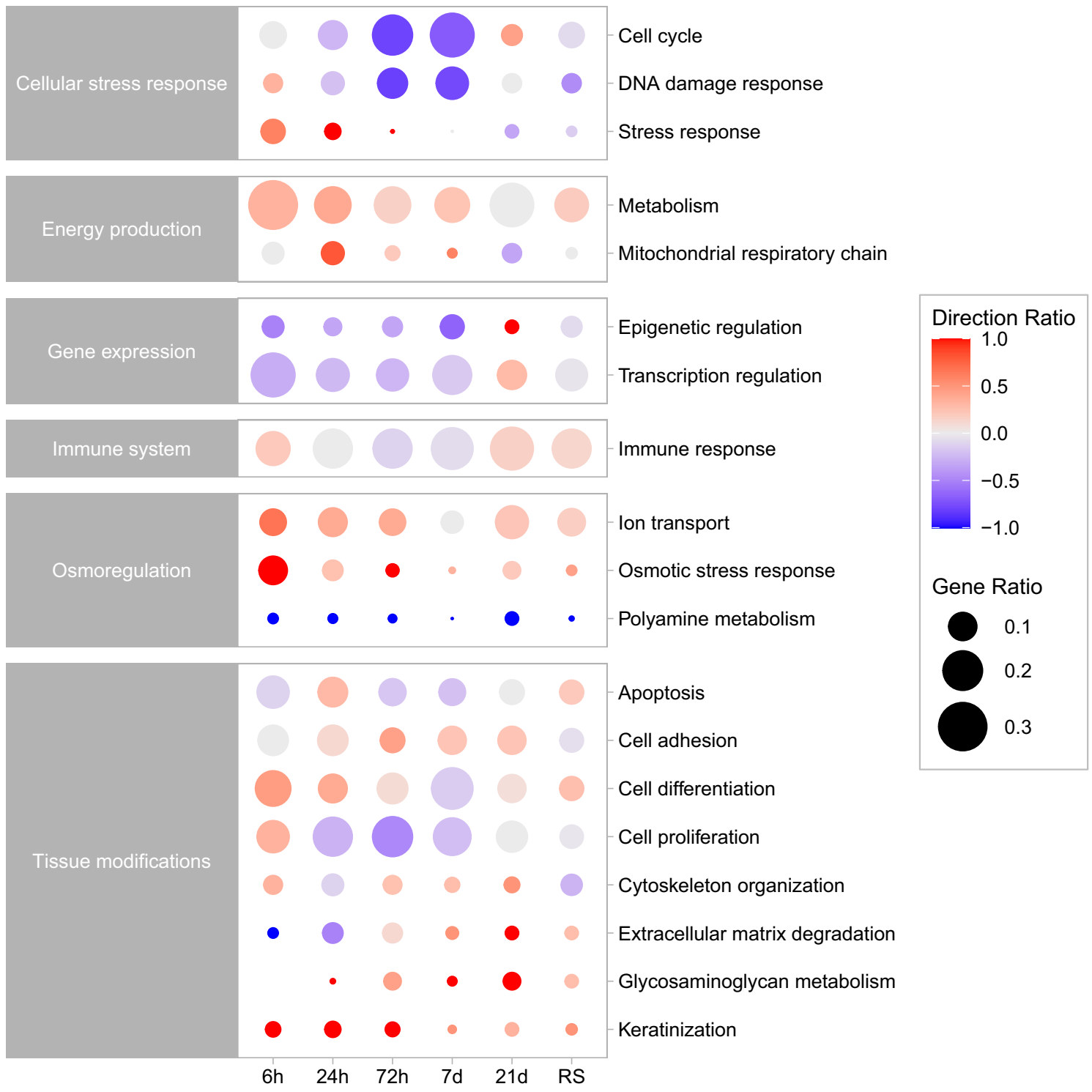

Figure 6. Changes in ratio and expression direction of differentially expressed genes grouped by functions along the acclimation timeline. Circle sizes are proportional to the gene number ratio for a specific function at a certain time point. Circle colours correspond to the ratio of the upregulated (red circles) vs downregulated (blue circles) genes for the function at that time point; the fuller the colour, the higher the proportion of up- or downregulated genes (e.g. 1.0 =all genes are upregulated; $0=$ half of the genes are upregulated, half are downregulated; $-1.0=$ all genes are downregulated).

At 24 h post-transfer, there were 164 DEGs compared to time 0 (Suppl. Table 12). "Gland development" was among the enriched GO terms (Suppl. Table 13), and included genes related to secretion, such as sodium and chloride channels (CFTR, CLCN2, SLC12A2), cell proliferation (E2F7, FGF7, FOXM1), hormonal response to stress actors (CRHR1, PRLR), cytoskeleton and extra-cellular matrix organization genes (DIAPH3, SOX9). "Lipid metabolic process" was also enriched at $24 \mathrm{~h}$, with genes related to cell membrane glycosphingolipid and glycerophospholipid biosynthesis (B4GALNT1, PLAAT4) and genes involved in lipid transport, such as carnitine palmitoyltransferase 1A (CPT1A), known to be part of the mitochondrial fatty acid oxidation pathway, and already upregulated at $6 \mathrm{~h}$. The increased energetic demand was additionally manifested by the upregulation of NADH:ubiquinone oxidoreductase complex assembly factor 4 (NDUFAF4), and solute carrier family 24 member 48 (SLC25A48), among others. Several ion transport actors and osmotic stress response regulators still played a role at $24 \mathrm{~h}$ as did various transcription factors, repressors, and regulators (Suppl. Table 11). Some genes involved in the DNA damage response pathway also still showed differential expression. Notably, several genes involved in keratinization (CNFN, K1C1, KRT13, S100A11, TGM5) were upregulated compared to time 0, while there was a downregulation of genes involved in the extracellular matrix degradation (ADAMTS5, COL23A1, EFEMP2, PLOD2, THSD4). Tissue remodelling processes happening in transferred fish were additionally reflected by the differential expression of genes involved in the regulation of apoptosis (Suppl. Table 11), such as cytochrome 
C (CYC), solute carrier family 25 member 6 (SLC25A6) and voltage-dependent anion channel 2 (VDAC2), all thought to be involved in the mitochondrial apoptotic pathway.

Clustering revealed that most of the above-mentioned genes exhibited a transiently up- or down-regulated pattern in the first $24 \mathrm{~h}$, being differentially expressed compared to pre-transfer fish only in these early time points (Fig. 5a; Suppl. Fig. 2; Suppl. Table 14). The main differences between the 6 and 24 h post-transfer time points (109 DEGs; Suppl. Table 15), as portrayed by the many related enriched GO terms (Suppl. Table 16), lay in cell cycle and mitosis associated processes, with downregulation of over 30 genes with these functions at $24 \mathrm{~h}$.

Individuals from the $72 \mathrm{~h}$ time point compared with the $24 \mathrm{~h}$ post-transfer fish resulted in only 30 DEGs (Suppl. Table 17), including the downregulation of two heat shock protein coding genes (HSPE1, DNAJC15) involved in stress response. The comparison with fish pre-transfer identified 197 DEGs (Suppl. Table 18), and the strongest signal of this contrast was the downregulation of more than 30 genes (Suppl. Table 11) involved in mitotic cell cycle and cell population proliferation (Suppl. Table 19), including genes fundamental for G1/S and G2/M phase transitions of the cell cycle. Concurrently, genes involved in DNA replication and repair showed downregulation compared to time 0 (Suppl. Table 11). Branchial tissue modifications were still happening at $72 \mathrm{~h}$ with DEGs involved in extracellular matrix degradation including: $\mathrm{Ca}^{2+}$-activated cysteine protease calpains (CAPN2, CAPN5, CAPN8), and matrix metallopeptidase 8 (MMP8), known to play a role in the breakdown of the extracellular matrix during tissue remodelling, as well as several glycoproteins with cell adhesion functions, such as CEA cell adhesion molecules (CEACAM5, CEACAM6). Genes belonging to the glycosaminoglycan-or mucopolysaccharides-biosynthesis pathway were upregulated at $72 \mathrm{~h}$ compared to pre-transfer conditions (Suppl. Table 11).

After 7 days from the start of the hyperosmotic challenge there were 423 DEGs compared to pre-transfer fish at time 0 (Fig. 4; Suppl. Table 20). This observed high number of differentially expressed genes could be an effect of the small sample size for this time-point $(n=3)$. Numerous GO terms were enriched (Suppl. Table 21), and over 80 genes, mostly downregulated compared to time 0 , pertained to mitotic cell cycle as well as cell proliferation and differentiation processes (Suppl. Table 11). Seven-day post-transfer fish gills were still showing significant changes in the expression of several ion channels, as well as genes implicated in energy production and tissue modifications, such as cell adhesion, cytoskeleton organization, mucopolysaccharide metabolism, and extracellular matrix degradation (Suppl. Table 11).

The last time point at 21 days post transfer exhibited 139 DEGs (Suppl. Table 22) in comparison with pretransfer fish. There was no functional enrichment for these genes, which were involved in a variety of processes (Suppl. Table 11). Osmoregulation was still under transition, with the upregulation of two typical seawater sodium-coupled transporters, the ATPase $\mathrm{Na}^{+} / \mathrm{K}^{+}$transporting subunit alpha 1 (ATP1A1) and the solute carrier family 12 member 2 (SLC12A2). While cell cycle and energy production genes were not differentially expressed at 21 days, gene expression related genes and tissue organization were upregulated compared to time 0 (Suppl. Table 11). Moreover, two genes involved in the biosynthesis of mucopolysaccharides (GALT-1, ST3GAL1) showed upregulation, joining B3GNT7, CHST3, ST3GAL2 that were already upregulated earlier in the acclimation.

Expression signatures leading to adaptation. Additional clustering analyses focused on the identification of genes putatively critical to long-term acclimation to elevated salinity in the Arabian pupfish. Starting from a subset of genes differentially expressed between the two populations at time 0 , the focus was placed on 69 DEGs which progressively resembled the expression levels of the Red Sea population along the experimental timeline and are agreed on by the clustering and ImpulseDE2 (Suppl. Table 23). Overall, some functions appeared earlier than others along the acclimation window (Fig. 6). For example, many genes implicated in osmotic stress response and osmoregulation (CA4, CFTR, CLCN2, IMPA1, KCNJ1, STK39, USP2, WNK2) were among the first to steadily change expression, between 6 and $24 \mathrm{~h}$ from the start of the exposure. Cornifelin (CNFN), a component of the cornified cell envelope, and glycoprotein M6B (GPM6B), a key upstream regulator of genes involved in actin cytoskeleton organization, were upregulated at every time point post-transfer. Similarly, genes involved in the metabolism of polyamines (ODC1, PAOX), important in hyposaline acclimation in teleosts, were downregulated from the first $24 \mathrm{~h}$ of exposure. As time progressed more genes changed their expression to match that of the seawater population. At $72 \mathrm{~h}$ post-transfer, the functions of these genes were related to changes in tissue organization and permeability, with the upregulation of calpain 2 (CAPN2) and microfibril associated protein 4 (MFAP4), both part of the extracellular matrix degradation pathway, and the downregulation of the water channel aquaporin 3 (AQP3). Moreover, some genes involved in mucopolysaccharide metabolism (B3GNT7, CHST3, GALT-1) started to be upregulated at $72 \mathrm{~h}$, while others (ST3GAL1, ST3GAL2) showed upregulation after 7 days. From 7 days of exposure to sea water, the transferred fish started to change the expression of branchial genes involved in lipid metabolism, showing upregulation of neutral cholesterol ester hydrolase 1 (NCEH1) and downregulation of low-density lipoprotein receptor (LDLR), both involved in lipoprotein and cholesterol metabolism. The transient receptor potential cation channel subfamily $\mathrm{V}$ member 4 (TRPV4), a non-selective cation channel involved in osmotic pressure regulation, was also downregulated from 7 day post-transfer. Finally, at the end of the experimental acclimation period, 21 days post-transfer, there was a downregulation of glycine decarboxylase (GLDC), involved in osmotic regulation, and arginase 1 (ARG1), another component of the polyamine metabolism pathway.

\section{Discussion}

Arabian pupfish from isolated nearly-freshwater ponds (1.5 ppt) have been found to be genetically connected to individuals found in highly saline Red Sea (43 ppt) lagoons downstream of dry riverbeds (called "wadies") 39 . One of the possible explanations for these findings is for desert pond pupfish to be sporadically flushed out to the sea through the wadies by flash floods, where they would need to rapidly acclimate to the new environment 
conditions, salinity in particular. This study time course transplantation experiment tested and demonstrated the potential of Arabian pupfish to survive and acclimate to such an abrupt salinity increase. Moreover, comparing the gill gene expression profiles of the native populations, as well as the changes across a salinity challenge from hours to weeks post-transfer, enabled the separation between short- and longer-term osmotic stress responses, and the investigation of the processes that would allow pupfish to adapt to the high salinity typical of the Red Sea environment. The native nearly-freshwater pupfish were able to acclimate to the abrupt increase in water salinity by means of expression changes in a large number of branchial genes. A subset of genes whose expression changed with the salinity exposure to resemble those of native seawater individuals revealed the importance of related functions in long-term acclimation.

The two populations at time 0 displayed the largest difference in gene expression of the whole experiment. Although partially expected because of the different genetic origin and native environment, the magnitude of this result was still surprising given the months spent in the same acclimation conditions, salinity excepted. The main source of expression divergence between the two native populations was osmoregulation, as well as the primary function at play during pupfish acclimation to high salinity. When in seawater, teleosts need to extrude passively accumulated salts through a variety of branchial ion transporters ${ }^{2}$. Accordingly, the Arabian pupfish Red Sea population upregulated ion transporters and osmoregulation related genes typically found in marine teleosts $^{9,72}$. The expression of many of these genes was quickly upregulated following high salinity exposure in desert pond fish and maintained along the entire acclimation timeline. For instance, genes involved in chloride ion secretion in marine-type ionocytes, such as cystic fibrosis transmembrane conductance regulator (CFTR) and $\mathrm{Na}^{+} / \mathrm{K}^{+} / \mathrm{Cl}^{-}$transporter (NKCC1 or SLC12A2) ${ }^{9,73}$, were upregulated in transferred pupfish already from 6 and $24 \mathrm{~h}$, respectively. Accordingly, in another pupfish species, Cyprinodon nevadensis amargosae, CFTR and NKCC1 gill mRNA levels increased within a similar time frame post-transfer into seawater and remained elevated throughout the 2 week experiment ${ }^{74}$, and upregulation of these two genes was also found in the gills of mummichog (Fundulus heteroclitus) within $24 \mathrm{~h}$ post-transfer from brackish to seawater ${ }^{5}$. Involved in the activation of NKCC1 are two other genes, WNK lysine deficient protein kinase 2 (WNK2) and serine/threonine kinase 39 $(\mathrm{STK} 39)^{73,75,76}$, also differentially expressed across the timeline in Arabian pupfish. WNK2 has indeed been found to regulate NKCC1 activation in Xenopus oocytes ${ }^{77}$, and its upregulation at every time point post-transfer to hyperosmotic water was also reported in the gills of the butterfish Pampus argenteus ${ }^{78}$. Likewise, Flemmer et al. ${ }^{75}$ reported the upregulation of STK39 in seawater-acclimated mummichog gills, and additionally linked it to the increased expression of NKCC1 in the same samples. The prompt upregulation of marine-type ion transporters and osmoregulatory genes in desert pond pupfish exposed to seawater to quickly resemble the Red Sea population levels confirms the importance of these genes in osmoregulation to highly saline conditions and reveals the high degree of conservation in osmoregulatory mechanisms among different fish species, Arabian pupfish included.

Another fundamental component of teleost osmoregulation in salt water is the myo-inositol biosynthesis (MIB) pathway, through which the compatible organic osmolyte myo-inositol is synthetized and accumulated inside cells during osmotic stress for protection from salinity-induced damage ${ }^{79}$. The two enzymes constituting the MIB pathway, inositol monophosphatase 1 (IMPA1) and myo-inositol phosphate synthase (MIPS or ISYNA1), were both differentially expressed in high-salinity exposed pupfish. Accordingly, both genes were also upregulated following seawater transfer in other euryhaline fishes, such as eels, Anguilla anguilla ${ }^{80}$, and turbots, Scophthalmus maximus ${ }^{81}$, where the MIB pathway knockdown was directly implicated in causing weakened gill osmoregulation and reduced survival ${ }^{82}$. The MIB pathway is therefore an important osmoregulation mechanism in seawater across several different species. However, the transient upregulation of MIPS in the first $24 \mathrm{~h}$ only highlights the importance of this pathway in the short-term osmotic stress response of the Arabian Pupfish.

In hyposaline waters fish are susceptible to passive ion loss and need to compensate by active uptake of osmolytes from the surrounding water ${ }^{1}$. In Arabian pupfish, chloride uptake is likely accomplished by chloride ion channel protein 2 (CLCN2), typically found in freshwater ionocytes ${ }^{83,84}$, which was highly expressed in desert pond individuals pre-transfer, and decreased from $24 \mathrm{~h}$ of high salinity exposure onward. Rainbow trout (Oncorhynchus mykiss) ionocytes ${ }^{84}$ and a Sacramento splittail, Pogonichthys macrolepidotus, population exposed to seawater ${ }^{20}$ also show this pattern, indicating the importance of this chloride channel in a variety of fish species inhabiting freshwater environments, where chloride uptake from the surrounding water is a key aspect of osmoregulation. Conversely, desert pond Arabian pupfish lack most of the previously described mechanisms for the uptake of sodium ${ }^{8,10}$, and might possibly exclusively rely on specialized isoforms of $\mathrm{Na}^{+} / \mathrm{K}^{+}$-ATPase (NKA) subunits for its import. Although the NKA gene is usually identified in marine acclimated teleosts, where it is part of the ion secretion machinery, in Arabian pupfish different transcripts annotated to the $\alpha-1$ subunit gene were upregulated in desert pond individuals, and only one transcript was upregulated in Red Sea pupfish. While this could be an indication of population-specific NKA subunit $\alpha-1$ isoforms ${ }^{20}$, it is likely that salinity-dependent isoforms with opposite functions of ion uptake in hyposaline water and salt secretion in seawater exist in this species, as previously described for several euryhaline teleosts ${ }^{85-90}$. In the climbing perch (Anabas testudines) and in salmonids, NKA $\alpha-1$ isoform a expression levels are highest in freshwater and decrease post-transfer to seawater, while other isoform mRNA expressions increase following exposure ${ }^{87,91}$. Accordingly, some of the NKA a-1 subunit coding transcripts showed a steady decreasing pattern along the exposure timeline in transferred pupfish, with one transcript resulting in a 4.5-fold downregulation at the end of the experimental timeline, which could be an indication of acclimation to the seawater habitat, where sodium uptake is not needed anymore. Revealed Arabian pupfish hyperosmoregulatory mechanisms could represent a new model for fish branchial ion absorption at low salinities and confirm the wide diversity of evolutionarily distinct branchial adaptations to hyposaline environments in teleosts. Overall, the main mechanisms differentiating Arabian pupfish natural populations pertain to osmoregulation, and rapid acclimation from near-freshwater to highly saline waters involves adjusting the gill gene expression to resemble the osmoregulatory processes typical to the long-term adapted seawater population. 
The second major difference between the two Arabian pupfish populations concerned the immune system, with several genes involved in the inflammatory and immune responses also differentially regulated post-transfer. In teleosts, salinity has been known to have intricate impacts on the immune system ${ }^{34,92,93}$. While osmotic stress has been found to increase the nonspecific immune response, a depression of the acquired immune response has also been reported owing to trade-offs in resource allocation ${ }^{34}$. Red Sea population and translocated desert pond fish showed however overexpression of acquired immune response components, such as immunoglobulins (Ig) and major histocompatibility complex class I-related (MR1). The immune response capacities are therefore likely not impacted during acclimation to seawater in Arabian pupfish, but rather they might actually be suppressed in near-freshwater, as opposed to what usually happens in salmonids and other fish species ${ }^{34}$. Another possible explanation for the elicitation of the Arabian pupfish adaptive immune response in seawater could lie in differences in pathogen attributes between salinities of the experimental setup. Gills indeed represent a major site for pathogen entry and consequent defence mechanism elicitation ${ }^{94}$, and salinity has been known to influence several pathogen characteristics, such as distribution ${ }^{95,96}$ and virulence ${ }^{97,98}$. Regardless of the reason, other fishes have been shown to not suffer from immune depression in seawater, such as Nile tilapia, Oreochromis niloticus ${ }^{99}$, as well as Acanthopagrus latus and Lates calcarifer, where plasma Ig levels increase with water salinity ${ }^{100}$. Likewise, hyperosmotic immersion of Paralichthys olivaceus boosts branchial major histocompatibility complex expression and the overall mucosal immune response $24-48 \mathrm{~h}$ post-exposure ${ }^{101}$. Indeed, a crucial role in immunity and defence in teleosts is exerted by mucosal surfaces ${ }^{102}$. Fish gills, skin and gut are coated with a thin mucus layer which acts as a barrier from the surrounding environment and is characterized by physical and antimicrobial defensive functions ${ }^{94,103}$, but a role in osmoregulation has also been suggested ${ }^{104,105}$. Two mucin-like transcripts were upregulated in Red Sea Arabian pupfish, as well as at $24 \mathrm{~h}$ and 7 days post-transfer in desert pond fish. Moreover, several genes related to O-linked glycosylation of mucins, glycosaminoglycan metabolism and mucus production ${ }^{106}$ were upregulated both in Red Sea individuals and in seawater-exposed desert pond fish. Accordingly, in Anguilla japonica mucosal tissues, seawater elicits an increase in mucus cell numbers and secretion, possibly to trap sodium ions ${ }^{105}$. Similar findings were reported for Salmo salar, in addition to salinity-driven modifications of mucin biochemistry ${ }^{107}$, that were also later described in other euryhaline fishes ${ }^{108,109}$. As the molecular results suggest, increased gill mucus production might be at play in seawater in Arabian pupfish and could be another aspect of their acclimation strategy to hyperosmotic environments.

While osmoregulation and immune response were revealed to be important in long-term adaptation to seawater, a series of short-term and transient response mechanisms were also elicited during the acclimation timeline. Abrupt increases in ion concentration can lead to macromolecular damage in exposed fish epithelia. An increase in sodium, for example, has been linked to cell membrane damage ${ }^{23}$ through lipid peroxidation, catalysed by lipoxygenases in response to stress ${ }^{28}$. Two lipoxygenases (ALOXE3, ALOXE15B) were indeed upregulated in Arabian pupfish gills $6 \mathrm{~h}$ post-transfer, and were also identified in similar seawater transfer experiments on eels ${ }^{110}$. Such membrane disruption can lead to the activation of the so-called cellular stress response (CSR), which encompasses defence mechanisms to protect and repair damaged cellular components and restore homeostasis ${ }^{23,28}$. The CSR machinery responds to sodium-destabilized proteins by overexpressing molecular chaperones, such as heat shock protein ${ }^{23}$, two of which were temporarily upregulated in Arabian pupfish at $24 \mathrm{~h}$, as well as in a hyperosmotic challenged Sacramento splittail population ${ }^{20}$. Rising intracellular sodium levels can also cause nucleic acid structural disruptions ${ }^{23}$, and consequently, increased expressions of DNA damage related genes are often reported as part of the CSR following hyperosmotic stress in teleosts ${ }^{26,27,70}$. In Arabian pupfish several DNA damage related genes were transiently upregulated especially in the first $24 \mathrm{~h}$ of exposure, like serum/glucocorticoid regulated kinase 1 (SGK1), and similarly increased in other fish following acute seawater challenges ${ }^{12,111}$. Hence, in the first hours of high salinity challenge, gill acclimation in Arabian pupfish is dominated by the onset of macromolecular damage followed by the cellular stress response machinery initiating the repair of the compromised processes to restore homeostasis.

Another aspect of hyperosmotic-induced CSR, at least in cultured human cells, is the inhibition of transcriptional and translational activities ${ }^{24}$. Equivalent to other species, such as the climbing perch ${ }^{31}$, Arabian pupfish exhibited a downregulation of transcription related genes following seawater exposure, which might be a mechanism to prevent the replication of high salinity-damaged DNA. An inhibition in transcription and translation might also explain the onset of cell cycle arrest that was identified in both Arabian pupfish and climbing perch ${ }^{31}$ via a downregulation of large sets of cell cycle and mitosis involved genes during the acclimation to seawater. In support of these findings, an immunocytochemistry study in tilapia (Oreochromis mossambicus) observed a G2 phase arrest in the mitotic cycle of gill cells over a period of 16-72 h post-seawater exposure ${ }^{112}$. Days to weeks after the start of the hyperosmotic challenge, an inhibition of transcriptional activity and simultaneous cell cycle arrest might represent a strategy for the fish to prevent the replication of damaged DNA, preserve energy and buy time to respond to macromolecular damage caused by the increase in ion concentration.

For longer-term acclimation to seawater, euryhaline fish gills must undergo profound remodelling events in order to switch from an ion absorbing epithelium to an ion secreting one. Arabian pupfish started displaying processes involved in tissue remodelling from the first hours of salinity exposure. Likely to allow a rapid reorganization of the gill epithelium to reverse the ion transport direction, a transient increase in cell proliferation and differentiation related genes was uncovered, as seen in the gills of euryhaline tilapia in the first $8 \mathrm{~h}$ of seawater exposure $^{112}$. At the same time, genes involved in keratinization, a process by which keratin accumulate inside epithelial tissue cells to provide barrier-like functions, started to be upregulated. Keratinization gene expression has been found to be salinity dependent in tilapia ${ }^{113}$ and to be upregulated following air exposure in the skin of the mangrove rivulus, Kryptolebias marmoratus ${ }^{114}$. Keratinization may represent a strategy to reduce the amount of water loss during dehydration, possibly also following increased environmental salinity, as seen in Arabian pupfish. Abrupt seawater transfer therefore elicited the rapid activation of gill tissue remodelling pathways, such 
as cell proliferation and keratinization, already in the first $6 \mathrm{~h}$ of exposure. Such a prompt response to salinity increases is one of the most striking evidence of the extensive branchial plasticity in this pupfish.

Programmed cell death, or apoptosis, of high salinity-damaged cells and freshwater-type ionocytes represents another of the first steps in gill epithelium remodelling, essential for full acclimation to seawater ${ }^{23}$. A transient upregulation of cytochrome c (CYC) and other genes involved in the mitochondrial apoptotic pathway was seen in Arabian pupfish at $24 \mathrm{~h}$. This has been previously recorded in mummichog in response to osmotic stresses ${ }^{19}$, and is supported by a microscopy study in Mozambique tilapia revealing increased branchial apoptotic freshwater ionocytes one day after transfer to seawater ${ }^{115}$. At $24 \mathrm{~h}$ post-transfer, genes related to cell adhesion began to be upregulated, and cytoskeleton and extracellular matrix organization functions showed increased expression from $72 \mathrm{~h}$ of exposure. Cell adhesion and extracellular matrix pathway upregulation was similarly reported in Sacramento splittails between one and seven days into the acclimation to elevated salinity ${ }^{20,21}$, and branchial cell cytoskeleton reorganization is largely recognized as a fundamental aspect of salinity acclimation in teleosts ${ }^{12,13,32}$. In the first days following seawater exposure, Arabian pupfish gill remodelling hence continued through apoptosis and modifications of cell adhesion, cytoskeleton and extracellular matrix, in order for the transferred fish branchial epithelium to better perform in the changed environment.

As a consequence of tissue remodelling events, an upregulation of mitochondrial respiratory chain and metabolism related genes is also expected to support the increased energy demand, as previously found in similar experiments of euryhaline fish translocation ${ }^{19,22,31}$. Analogously, in Arabian pupfish there was an overall upregulation of metabolism related genes up to 7 days post-transfer, while genes involved in mitochondrial respiration were overexpressed especially between days one and seven, which is consistent with the time frame for major gill remodelling processes in other species ${ }^{16,17,20}$. In a similar fashion to other euryhaline teleosts, seawater exposed pupfish are therefore affected by transient and longer-lasting gill tissue modifications occurring from the first hours to several days after the beginning of the exposure, and potentially resulting in durable modifications which allow longer-term acclimation to the highly saline environment.

Arabian pupfish inhabit profoundly divergent environments of the Arabian Peninsula, ranging from nearlyfreshwater ponds found in desert areas to highly saline Red Sea coastal lagoons. The plasticity of these fish under steep increases in water salinity is hypothesized to play a major role in the colonization potential of this species ${ }^{39}$. By simulating the exposure to high salinity from near-freshwater, this study tested Arabian pupfish potential to survive flash flood events and to move between highly different salinity environments. Not only key processes for a successful acclimation were identified, but also the importance of their timing was uncovered. Arabian pupfish branchial salinity-elicited pathways revealed osmoregulation, immune system and mucus production to be rapid but also long-term acclimation mechanisms to the new environment. In the short-term, cellular stress response processes were triggered, which prevented the fish from suffering permanent damage following acute hyperosmotic exposure. Later in the acclimation, pathways involved in gill epithelium modification and remodelling equipped the organism with lasting adaptations to the increased salinity. While some of the processes occurring during the acclimation timeline resembled mechanisms of seawater exposure previously reported in other euryhaline fish species, others, such as increased mucus production and keratinization, represent less common strategies for high salinity acclimation in teleosts. Overall, the branchial processes revealed in this nearly-freshwater Arabian pupfish population during high salinity acclimation sheds light into this nonmodel euryhaline species colonization potential of seawater habitats. A large set of differentially timed molecular mechanisms plays a role in the plastic reorganization of the gills in hyperosmotic environments that allows for the expansion of euryhaline teleosts into a wide variety of different habitats.

\section{Data availability}

Raw sequence data are available through the National Center for Biotechnology Information Sequence Read Archive under BioProject PRJNA722804.

Received: 24 May 2021; Accepted: 17 August 2021

Published online: 13 September 2021

\section{References}

1. Edwards, S. L. \& Marshall, W. S. In Euryhaline Fishes. Fish Physiology Vol. 32 (eds Farrell Stephen, A. P. et al.) 1-44 (Academic Press, 2012).

2. Evans, D. H., Piermarini, P. M. \& Choe, K. P. The multifunctional fish gill: Dominant site of gas exchange, osmoregulation, acid-base regulation, and excretion of nitrogenous waste. Physiol. Rev. 85, 97-177. https://doi.org/10.1152/physrev.00050.2003 (2005).

3. Kultz, D. Physiological mechanisms used by fish to cope with salinity stress. J. Exp. Biol. 218, 1907-1914. https://doi.org/10. 1242/jeb.118695 (2015).

4. Schultz, E. T. \& McCormick, S. D. In Euryhaline Fishes. Fish Physiology Vol. 32 (eds Farrell, A. P. et al.) 477-533 (Academic Press, 2012).

5. Scott, G. R., Richards, J. G., Forbush, B., Isenring, P. \& Schulte, P. M. Changes in gene expression in gills of the euryhaline killifish Fundulus heteroclitus after abrupt salinity transfer. Am. J. Physiol. Cell Physiol. 287, C300-C309. https://doi.org/10.1152/ ajpcell.00054.2004 (2004).

6. Deane, E. E. \& Woo, N. Y. Differential gene expression associated with euryhalinity in sea bream (Sparus sarba). Am. J. Physiol. Regul. Integr. Comp. Physiol. 287, R1054-R1063. https://doi.org/10.1152/ajpregu.00347.2004 (2004).

7. Scott, G. R., Claiborne, J. B., Edwards, S. L., Schulte, P. M. \& Wood, C. M. Gene expression after freshwater transfer in gills and opercular epithelia of killifish: Insight into divergent mechanisms of ion transport. J. Exp. Biol. 208, 2719-2729. https://doi.org/ 10.1242/jeb.01688 (2005).

8. Dymowska, A. K., Hwang, P. P. \& Goss, G. G. Structure and function of ionocytes in the freshwater fish gill. Respir. Physiol. Neurobiol. 184, 282-292. https://doi.org/10.1016/j.resp.2012.08.025 (2012). 
9. Hiroi, J. \& McCormick, S. D. New insights into gill ionocyte and ion transporter function in euryhaline and diadromous fish. Respir. Physiol. Neurobiol. 184, 257-268. https://doi.org/10.1016/j.resp.2012.07.019 (2012).

10. Hsu, H. H., Lin, L. Y., Tseng, Y. C., Horng, J. L. \& Hwang, P. P. A new model for fish ion regulation: Identification of ionocytes in freshwater- and seawater-acclimated medaka (Oryzias latipes). Cell Tissue Res. 357, 225-243. https://doi.org/10.1007/s00441014-1883-z (2014).

11. Hwang, P. P. \& Lin, L. Y. In The Physiology of Fishes Vol. 4 (eds Evans, D. H. et al.) 205-233 (CRC Press, 2013).

12. Evans, T. G. \& Somero, G. N. A microarray-based transcriptomic time-course of hyper- and hypo-osmotic stress signaling events in the euryhaline fish Gillichthys mirabilis: Osmosensors to effectors. J. Exp. Biol. 211, 3636-3649. https://doi.org/10.1242/jeb. 022160 (2008)

13. Fiol, D. F. \& Kultz, D. Osmotic stress sensing and signaling in fishes. FEBS J. 274, 5790-5798. https://doi.org/10.1111/j.17424658.2007.06099.x (2007).

14. Kultz, D. The combinatorial nature of osmosensing in fishes. Physiology (Bethesda) 27, 259-275. https://doi.org/10.1152/physi ol.00014.2012 (2012).

15. Komoroske, L. M. et al. Sublethal salinity stress contributes to habitat limitation in an endangered estuarine fish. Evol. Appl. 9, 963-981. https://doi.org/10.1111/eva.12385 (2016).

16. Foskett, J. K., Logsdon, C. D., Turner, T., Machen, T. E. \& Bern, H. A. Differentiation of the chloride extrusion mechanism during seawater adaptation of a teleost fish, the cichlid Sarotherodon mossambicus. J. Exp. Biol. 93, 209-224 (1981).

17. Katoh, F. \& Kaneko, T. Short-term transformation and long-term replacement of branchial chloride cells in killifish transferred from seawater to freshwater, revealed by morphofunctional observations and a newly established "time-differential double fluorescent staining” technique. J. Exp. Biol. 206, 4113-4123. https://doi.org/10.1242/jeb.00659 (2003).

18. Uchida, K., Kaneko, T., Miyazaki, H., Hasegawa, S. \& Hirano, T. Excellent salinity tolerance of mozambique tilapia (Oreochromis mossambicus): Elevated chloride cell activity in the branchial and opercular epithelia of the fish adapted to concentrated seawater. Zool. Sci. 17, 149-160. https://doi.org/10.2108/zsj.17.149 (2000).

19. Whitehead, A., Roach, J. L., Zhang, S. \& Galvez, F. Salinity- and population-dependent genome regulatory response during osmotic acclimation in the killifish (Fundulus heteroclitus) gill. J. Exp. Biol. 215, 1293-1305. https://doi.org/10.1242/jeb.062075 (2012).

20. Mundy, P. C., Jeffries, K. M., Fangue, N. A. \& Connon, R. E. Differential regulation of select osmoregulatory genes and $\mathrm{Na}^{+} /$ $\mathrm{K}^{+}$-ATPase paralogs may contribute to population differences in salinity tolerance in a semi-anadromous fish. Comp. Biochem. Physiol. A Mol. Integr. Physiol. 240, 110584. https://doi.org/10.1016/j.cbpa.2019.110584 (2020).

21. Jeffries, K. M. et al. Divergent transcriptomic signatures in response to salinity exposure in two populations of an estuarine fish. Evol. Appl. 12, 1212-1226. https://doi.org/10.1111/eva.12799 (2019).

22. Lam, S. H. et al. Differential transcriptomic analyses revealed genes and signaling pathways involved in iono-osmoregulation and cellular remodeling in the gills of euryhaline Mozambique tilapia, Oreochromis mossambicus. BMC Genomics 15, 921. https:// doi.org/10.1186/1471-2164-15-921 (2014).

23. Evans, T. G. \& Kultz, D. The cellular stress response in fish exposed to salinity fluctuations. J. Exp. Zool. A Ecol. Integr. Physiol. 333, 421-435. https://doi.org/10.1002/jez.2350 (2020).

24. Burg, M. B., Ferraris, J. D. \& Dmitrieva, N. I. Cellular response to hyperosmotic stresses. Physiol. Rev. 87, 1441-1474. https:// doi.org/10.1152/physrev.00056.2006 (2007).

25. Tine, M., Bonhomme, F., McKenzie, D. J. \& Durand, J. D. Differential expression of the heat shock protein Hsp70 in natural populations of the tilapia, Sarotherodon melanotheron, acclimatised to a range of environmental salinities. BMC Ecol. 10, 11. https://doi.org/10.1186/1472-6785-10-11 (2010).

26. Whitehead, A., Zhang, S., Roach, J. L. \& Galvez, F. Common functional targets of adaptive micro- and macro-evolutionary divergence in killifish. Mol. Ecol. 22, 3780-3796. https://doi.org/10.1111/mec.12316 (2013).

27. Brennan, R. S., Galvez, F. \& Whitehead, A. Reciprocal osmotic challenges reveal mechanisms of divergence in phenotypic plasticity in the killifish Fundulus heteroclitus. J. Exp. Biol. 218, 1212-1222. https://doi.org/10.1242/jeb.110445 (2015).

28. Kultz, D. Molecular and evolutionary basis of the cellular stress response. Annu. Rev. Physiol. 67, 225-257. https://doi.org/10. 1146/annurev.physiol.67.040403.103635 (2005).

29. Takei, Y. \& Hwang, P.-P. In Biology of Stress in Fish-Fish Physiology Vol. 35 (eds Schreck, C. B. et al.) 207-249 (Academic Press, 2016).

30. Tseng, Y. C. \& Hwang, P. P. Some insights into energy metabolism for osmoregulation in fish. Comp. Biochem. Physiol. C Toxicol. Pharmacol. 148, 419-429. https://doi.org/10.1016/j.cbpc.2008.04.009 (2008).

31. Chen, X. L., Lui, E. Y., Ip, Y. K. \& Lam, S. H. RNA sequencing, de novo assembly and differential analysis of the gill transcriptome of freshwater climbing perch Anabas testudineus after 6 days of seawater exposure. J. Fish Biol. 93, 215-228. https://doi.org/10. $1111 /$ jfb. $13653(2018)$.

32. Nguyen, T. V., Jung, H., Nguyen, T. M., Hurwood, D. \& Mather, P. Evaluation of potential candidate genes involved in salinity tolerance in striped catfish (Pangasianodon hypophthalmus) using an RNA-Seq approach. Mar. Genomics 25, 75-88. https://doi. org/10.1016/j.margen.2015.11.010 (2016).

33. Bœuf, G. \& Payan, P. How should salinity influence fish growth?. Comp. Biochem. Physiol. C Toxicol. Pharmacol. 130, 411-423. https://doi.org/10.1016/s1532-0456(01)00268-x (2001).

34. Makrinos, D. L. \& Bowden, T. J. Natural environmental impacts on teleost immune function. Fish Shellfish Immunol. 53, 50-57. https://doi.org/10.1016/j.fsi.2016.03.008 (2016).

35. Morgan, J. D. \& Iwama, G. K. Effects of salinity on growth, metabolism, and ion regulation in juvenile rainbow and steelhead trout (Oncorhynchus mykiss) and fall chinook salmon (Oncorhynchus tshawytscha). Can. J. Fish. Aquat. Sci. 48, 2083-2094. https://doi.org/10.1139/f91-247 (1991).

36. Whitehead, A., Roach, J. L., Zhang, S. \& Galvez, F. Genomic mechanisms of evolved physiological plasticity in killifish distributed along an environmental salinity gradient. Proc. Natl. Acad. Sci. U.S.A. 108, 6193-6198. https://doi.org/10.1073/pnas.1017542108 (2011).

37. Kozak, G. M., Brennan, R. S., Berdan, E. L., Fuller, R. C. \& Whitehead, A. Functional and population genomic divergence within and between two species of killifish adapted to different osmotic niches. Evolution 68, 63-80. https://doi.org/10.1111/evo.12265 (2014).

38. Hrbek, T. \& Meyer, A. Closing of the Tethys Sea and the phylogeny of Eurasian killifishes (Cyprinodontiformes: Cyprinodontidae). J. Evol. Biol. 16, 17-36. https://doi.org/10.1046/j.1420-9101.2003.00475.x (2003).

39. Schunter, C. et al. Desert fish populations tolerate extreme salinity change to overcome hydrological constraints. bioRxiv. https:// doi.org/10.1101/2021.05.14.444120 (2021).

40. Marshall, J. C. et al. Go with the flow: The movement behaviour of fish from isolated waterhole refugia during connecting flow events in an intermittent dryland river. Freshw. Biol. 61, 1242-1258. https://doi.org/10.1111/fwb.12707 (2016).

41. Kerezsy, A., Balcombe, S. R., Tischler, M. \& Arthington, A. H. Fish movement strategies in an ephemeral river in the Simpson Desert, Australia. Austral Ecol. 38, 798-808. https://doi.org/10.1111/aec.12075 (2013).

42. Martin, C. H., Crawford, J. E., Turner, B. J. \& Simons, L. H. Diabolical survival in Death Valley: Recent pupfish colonization, gene flow and genetic assimilation in the smallest species range on earth. Proc. Biol. Sci. 283, 20152334. https://doi.org/10.1098/ rspb.2015.2334 (2016). 
43. Mossop, K. D. et al. Dispersal in the desert: Ephemeral water drives connectivity and phylogeography of an arid-adapted fish. J. Biogeogr. 42, 2374-2388. https://doi.org/10.1111/jbi.12596 (2015).

44. Collins, J. P., Young, C., Howell, J. \& Minckley, W. L. Impact of flooding in a Sonoran desert stream, including elimination of an endangered fish population (Poeciliopsis O. occidentalis, Poeciliidae). Southwest. Nat. 26, 415-423. https://doi.org/10.2307/ 3671085 (1981).

45. Meffe, G. K. Effects of abiotic disturbance on coexistence of predator-prey fish species. Ecology 65, 1525-1534. https://doi.org/ $10.2307 / 1939132(1984)$.

46. Lotan, R. Sodium, chloride and water balance in the euryhaline teleost Aphanius dispar (Rüppell) (Cyprinodontidae). Z. Vgl. Physiol. 65, 455-462. https://doi.org/10.1007/bf00299054 (1969).

47. Lotan, R. Osmotic adjustment in the euryhaline teleost Aphanius dispar (Cyprinodontidae). Z. Vgl. Physiol. 75, 383-387. https:// doi.org/10.1007/bf00630558 (1971).

48. Plaut, I. Resting metabolic rate, critical swimming speed, and routine activity of the euryhaline cyprinodontid, Aphanius dispar, acclimated to a wide range of salinities. Physiol. Biochem. Zool. 73, 590-596. https://doi.org/10.1086/317746 (2000).

49. Bolger, A. M., Lohse, M. \& Usadel, B. Trimmomatic: A flexible trimmer for Illumina sequence data. Bioinformatics 30, $2114-2120$. https://doi.org/10.1093/bioinformatics/btu170 (2014).

50. Andrews, S. FastQC: a quality control tool for high throughput sequence data. https://www.bioinformatics.babraham.ac.uk/ projects/fastqc (2010).

51. Song, L. \& Florea, L. Rcorrector: Efficient and accurate error correction for Illumina RNA-seq reads. Gigascience 4, 48. https:// doi.org/10.1186/s13742-015-0089-y (2015).

52. Grabherr, M. G. et al. Trinity: Reconstructing a full-length transcriptome without a genome from RNA-Seq data. Nat. Biotechnol. 29, 644 (2011).

53. Lafond-Lapalme, J., Duceppe, M. O., Wang, S., Moffett, P. \& Mimee, B. A new method for decontamination of de novo transcriptomes using a hierarchical clustering algorithm. Bioinformatics 33, 1293-1300. https://doi.org/10.1093/bioinformatics/btw793 (2017).

54. Haas, B. J. et al. De novo transcript sequence reconstruction from RNA-seq using the Trinity platform for reference generation and analysis. Nat. Protoc. 8, 1494-1512. https://doi.org/10.1038/nprot.2013.084 (2013).

55. Finn, R. D., Clements, J. \& Eddy, S. R. HMMER web server: Interactive sequence similarity searching. Nucleic Acids Res. 39, W29-W37. https://doi.org/10.1093/nar/gkr367 (2011).

56. Camacho, C. et al. BLAST+: Architecture and applications. BMC Bioinform. 10, 421. https://doi.org/10.1186/1471-2105-10-421 (2009).

57. Fu, L., Niu, B., Zhu, Z., Wu, S. \& Li, W. CD-HIT: Accelerated for clustering the next-generation sequencing data. Bioinformatics 28, 3150-3152. https://doi.org/10.1093/bioinformatics/bts565 (2012).

58. Langmead, B. \& Salzberg, S. L. Fast gapped-read alignment with Bowtie 2. Nat. Methods 9, 357-359. https://doi.org/10.1038/ nmeth.1923 (2012).

59. Simao, F. A., Waterhouse, R. M., Ioannidis, P., Kriventseva, E. V. \& Zdobnov, E. M. BUSCO: Assessing genome assembly and annotation completeness with single-copy orthologs. Bioinformatics 31, 3210-3212. https://doi.org/10.1093/bioinformatics/ btv351 (2015).

60. BioBam Bioinformatics. OmicsBox - Bioinformatics Made Easy. https://www.biobam.com/omicsbox (2019).

61. Huerta-Cepas, J. et al. eggNOG 5.0: A hierarchical, functionally and phylogenetically annotated orthology resource based on 5090 organisms and 2502 viruses. Nucleic Acids Res. 47, D309-D314. https://doi.org/10.1093/nar/gky1085 (2019).

62. Gotz, S. et al. High-throughput functional annotation and data mining with the Blast2GO suite. Nucleic Acids Res. 36, 3420-3435. https://doi.org/10.1093/nar/gkn176 (2008).

63. Patro, R., Duggal, G., Love, M. I., Irizarry, R. A. \& Kingsford, C. Salmon provides fast and bias-aware quantification of transcript expression. Nat. Methods 14, 417-419. https://doi.org/10.1038/nmeth.4197 (2017).

64. Love, M. I., Huber, W. \& Anders, S. Moderated estimation of fold change and dispersion for RNA-seq data with DESeq2. Genome Biol. 15, 550. https://doi.org/10.1186/s13059-014-0550-8 (2014).

65. Soneson, C., Love, M. I. \& Robinson, M. D. Differential analyses for RNA-seq: Transcript-level estimates improve gene-level inferences. F1000Research https://doi.org/10.12688/f1000research.7563.1 (2015).

66. Zhu, A., Ibrahim, J. G. \& Love, M. I. Heavy-tailed prior distributions for sequence count data: Removing the noise and preserving large differences. Bioinformatics 35, 2084-2092. https://doi.org/10.1093/bioinformatics/bty895 (2019).

67. Benjamini, Y. \& Hochberg, Y. Controlling the false discovery rate-A practical and powerful approach to multiple testing. J. R. Stat. Soc. Ser. B Stat. Methodol. 57, 289-300. https://doi.org/10.1111/j.2517-6161.1995.tb02031.x (1995).

68. Cui, W. et al. Comparative transcriptomic analysis reveals mechanisms of divergence in osmotic regulation of the turbot Scophthalmus maximus. Fish Physiol. Biochem. 46, 1519-1536. https://doi.org/10.1007/s10695-020-00808-6 (2020).

69. Lee, S. Y., Lee, H. J. \& Kim, Y. K. Comparative transcriptome profiling of selected osmotic regulatory proteins in the gill during seawater acclimation of chum salmon (Oncorhynchus keta) fry. Sci. Rep. 10, 1987. https://doi.org/10.1038/s41598-020-58915-6 (2020).

70. Su, H., Ma, D., Zhu, H., Liu, Z. \& Gao, F. Transcriptomic response to three osmotic stresses in gills of hybrid tilapia (Oreochromis mossambicus female $\times$ O. urolepis hornorum male). BMC Genomics 21, 110. https://doi.org/10.1186/s12864-020-6512-5 (2020).

71. Fischer, D. S., Theis, F. J. \& Yosef, N. Impulse model-based differential expression analysis of time course sequencing data. Nucleic Acids Res. 46, e119. https://doi.org/10.1093/nar/gky675 (2018).

72. Hwang, P. P., Lee, T. H. \& Lin, L. Y. Ion regulation in fish gills: Recent progress in the cellular and molecular mechanisms. Am. J. Physiol. Regul. Integr. Comp. Physiol. 301, R28-R47. https://doi.org/10.1152/ajpregu.00047.2011 (2011).

73. Marshall, W. S. Mechanosensitive signalling in fish gill and other ion transporting epithelia. Acta Physiol. (Oxf.) 202, 487-499. https://doi.org/10.1111/j.1748-1716.2010.02189.x (2011).

74. Lema, S. C., Carvalho, P. G., Egelston, J. N., Kelly, J. T. \& McCormick, S. D. Dynamics of gene expression responses for ion transport proteins and aquaporins in the gill of a euryhaline pupfish during freshwater and high-salinity acclimation. Physiol. Biochem. Zool. 91, 1148-1171. https://doi.org/10.1086/700432 (2018)

75. Flemmer, A. W. et al. Phosphorylation state of the $\mathrm{Na}^{+}-\mathrm{K}^{+}-\mathrm{Cl}^{-}$cotransporter (NKCC1) in the gills of Atlantic killifish (Fundulus heteroclitus) during acclimation to water of varying salinity. J. Exp. Biol. 213, 1558-1566. https://doi.org/10.1242/jeb.039644 (2010).

76. Delpire, E. \& Gagnon, K. B. SPAK and OSR1: STE20 kinases involved in the regulation of ion homoeostasis and volume control in mammalian cells. Biochem. J. 409, 321-331. https://doi.org/10.1042/BJ20071324 (2008).

77. Rinehart, J. et al. WNK2 kinase is a novel regulator of essential neuronal cation-chloride cotransporters. J. Biol. Chem. 286, 30171-30180. https://doi.org/10.1074/jbc.M111.222893 (2011).

78. Li, J. et al. Gill transcriptomes reveal expression changes of genes related with immune and ion transport under salinity stress in silvery pomfret (Pampus argenteus). Fish Physiol. Biochem. 46, 1255-1277. https://doi.org/10.1007/s10695-020-00786-9 (2020).

79. Yancey, P. H., Clark, M. E., Hand, S. C., Bowlus, R. D. \& Somero, G. N. Living with water stress: Evolution of osmolyte systems. Science 217, 1214-1222. https://doi.org/10.1126/science.7112124 (1982).

80. Kalujnaia, S., McVee, J., Kasciukovic, T., Stewart, A. J. \& Cramb, G. A role for inositol monophosphatase 1 (IMPA1) in salinity adaptation in the euryhaline eel (Anguilla anguilla). FASEB J. 24, 3981-3991. https://doi.org/10.1096/ff.10-161000 (2010). 
81. Cui, W. X. et al. myo-inositol facilitates salinity tolerance by modulating multiple physiological functions in the turbot Scophthalmus maximus. Aquaculture 527, 735451. https://doi.org/10.1016/j.aquaculture.2020.735451 (2020).

82. Ma, A. et al. Osmoregulation by the myo-inositol biosynthesis pathway in turbot Scophthalmus maximus and its regulation by anabolite and c-Myc. Comp. Biochem. Physiol. A Mol. Integr. Physiol. 242, 110636. https://doi.org/10.1016/j.cbpa.2019.110636 (2020).

83. Wang, Y. F., Yan, J. J., Tseng, Y. C., Chen, R. D. \& Hwang, P. P. Molecular physiology of an extra-renal $\mathrm{Cl}^{-}$uptake mechanism for body fluid $\mathrm{Cl}^{-}$homeostasis. Int. J. Biol. Sci. 11, 1190-1203. https://doi.org/10.7150/ijbs.11737 (2015).

84. Leguen, I., Le Cam, A., Montfort, J., Peron, S. \& Fautrel, A. Transcriptomic analysis of trout gill ionocytes in fresh water and sea water using laser capture microdissection combined with microarray analysis. PLoS One 10, e0139938. https://doi.org/10. 1371/journal.pone.0139938 (2015).

85. Richards, J. G., Semple, J. W., Bystriansky, J. S. \& Schulte, P. M. Na ${ }^{+} / \mathrm{K}^{+}$-ATPase alpha-isoform switching in gills of rainbow trout (Oncorhynchus mykiss) during salinity transfer. J. Exp. Biol. 206, 4475-4486. https://doi.org/10.1242/jeb.00701 (2003).

86. McCormick, S. D., Regish, A. M. \& Christensen, A. K. Distinct freshwater and seawater isoforms of $\mathrm{Na}^{+} / \mathrm{K}^{+}$-ATPase in gill chloride cells of Atlantic salmon. J. Exp. Biol. 212, 3994-4001. https://doi.org/10.1242/jeb.037275 (2009).

87. Bystriansky, J. S., Richards, J. G., Schulte, P. M. \& Ballantyne, J. S. Reciprocal expression of gill $\mathrm{Na}^{+} / \mathrm{K}^{+}-\mathrm{ATPase}$ alpha-subunit isoforms alphala and alphalb during seawater acclimation of three salmonid fishes that vary in their salinity tolerance. J. Exp. Biol. 209, 1848-1858. https://doi.org/10.1242/jeb.02188 (2006).

88. Tipsmark, C. K. et al. Switching of $\mathrm{Na}^{+}, \mathrm{K}^{+}$-ATPase isoforms by salinity and prolactin in the gill of a cichlid fish. J. Endocrinol. 209, 237-244. https://doi.org/10.1530/JOE-10-0495 (2011).

89. Urbina, M. A., Schulte, P. M., Bystriansky, J. S. \& Glover, C. N. Differential expression of $\mathrm{Na}^{+}, \mathrm{K}^{+}$-ATPase alpha-1 isoforms during seawater acclimation in the amphidromous galaxiid fish Galaxias maculatus. J. Comp. Physiol. B 183, 345-357. https://doi. org/10.1007/s00360-012-0719-y (2013).

90. Velotta, J. P. et al. Transcriptomic imprints of adaptation to fresh water: Parallel evolution of osmoregulatory gene expression in the Alewife. Mol. Ecol. 26, 831-848. https://doi.org/10.1111/mec.13983 (2017).

91. Ip, Y. K. et al. Roles of three branchial $\mathrm{Na}^{+}-\mathrm{K}^{+}$-ATPase alpha-subunit isoforms in freshwater adaptation, seawater acclimation, and active ammonia excretion in Anabas testudineus. Am. J. Physiol. Regul. Integr. Comp. Physiol. 303, R112-R125. https://doi. org/10.1152/ajpregu.00618.2011 (2012).

92. Birrer, S. C., Reusch, T. B. \& Roth, O. Salinity change impairs pipefish immune defence. Fish Shellfish Immunol. 33, 1238-1248. https://doi.org/10.1016/j.fsi.2012.08.028 (2012).

93. Delamare-Deboutteville, J., Wood, D. \& Barnes, A. C. Response and function of cutaneous mucosal and serum antibodies in barramundi (Lates calcarifer) acclimated in seawater and freshwater. Fish Shellfish Immunol. 21, 92-101. https://doi.org/10. 1016/j.fsi.2005.10.005 (2006).

94. Koppang, E. O., Kvellestad, A. \& Fischer, U. In Mucosal Health in Aquaculture (eds Beck, B. H. \& Peatman, E.) 93-133 (Academic Press, 2015).

95. Poulin, R., Blanar, C. A., Thieltges, D. W. \& Marcogliese, D. J. The biogeography of parasitism in sticklebacks: Distance, habitat differences and the similarity in parasite occurrence and abundance. Ecography 34, 540-551. https://doi.org/10.1111/j.16000587.2010.06826.x (2011).

96. Takemura, A. F., Chien, D. M. \& Polz, M. F. Associations and dynamics of Vibrionaceae in the environment, from the genus to the population level. Front. Microbiol. 5, 38. https://doi.org/10.3389/fmicb.2014.00038 (2014).

97. Nitzan, S., Shwartsburd, B. \& Heller, E. D. The effect of growth medium salinity of Photobacterium damselae subsp. piscicida on the immune response of hybrid bass (Morone saxatilis $\times$ M. chrysops). Fish Shellfish Immunol. 16, 107-116. https://doi.org/10. 1016/s1050-4648(03)00045-7 (2004).

98. Zheng, D. H. et al. Effect of temperature and salinity on virulence of Edwardsiella tarda to Japanese flounder, Paralichthys olivaceus (Temminck et Schlegel). Aquac. Res. 35, 494-500. https://doi.org/10.1111/j.1365-2109.2004.01044.x (2004).

99. Dominguez, M., Takemura, A., Tsuchiya, M. \& Nakamura, S. Impact of different environmental factors on the circulating immunoglobulin levels in the Nile tilapia, Oreochromis niloticus. Aquaculture 241, 491-500. https://doi.org/10.1016/j.aquac ulture.2004.06.027 (2004).

100. Mozanzadeh, M. T. et al. The effect of salinity on growth performance, digestive and antioxidant enzymes, humoral immunity and stress indices in two euryhaline fish species: Yellowfin seabream (Acanthopagrus latus) and Asian seabass (Lates calcarifer). Aquaculture 534, 736329. https://doi.org/10.1016/j.aquaculture.2020.736329 (2021).

101. Gao, Y., Tang, X., Sheng, X., Xing, J. \& Zhan, W. Antigen uptake and expression of antigen presentation-related immune genes in flounder (Paralichthys olivaceus) after vaccination with an inactivated Edwardsiella tarda immersion vaccine, following hyperosmotic treatment. Fish Shellfish Immunol. 55, 274-280. https://doi.org/10.1016/j.fsi.2016.05.042 (2016).

102. Salinas, I. The mucosal immune system of teleost fish. Biology 4, 525-539. https://doi.org/10.3390/biology4030525 (2015).

103. Reverter, M., Tapissier-Bontemps, N., Lecchini, D., Banaigs, B. \& Sasal, P. Biological and ecological roles of external fish mucus: A review. Fishes 3, 41. https://doi.org/10.3390/fishes3040041 (2018).

104. Shephard, K. L. Functions for fish mucus. Rev. Fish Biol. Fish. 4, 401-429. https://doi.org/10.1007/Bf00042888 (1994).

105. Wong, M. K. S. et al. A sodium binding system alleviates acute salt stress during seawater acclimation in eels. Zool. Lett. 3, 22. https://doi.org/10.1186/s40851-017-0081-8 (2017).

106. Malachowicz, M., Wenne, R. \& Burzynski, A. De novo assembly of the sea trout (Salmo trutta m. trutta) skin transcriptome to identify putative genes involved in the immune response and epidermal mucus secretion. PLoS One 12, e0172282. https://doi. org/10.1371/journal.pone.0172282 (2017).

107. Roberts, S. D. \& Powell, M. D. Comparative ionic flux and gill mucous cell histochemistry: Effects of salinity and disease status in Atlantic salmon (Salmo salar L.). Comp. Biochem. Physiol. A Mol. Integr. Physiol. 134, 525-537. https://doi.org/10.1016/s10956433(02)00327-6 (2003).

108. Mylonas, C. C. et al. Growth performance and osmoregulation in the shi drum (Umbrina cirrosa) adapted to different environmental salinities. Aquaculture 287, 203-210. https://doi.org/10.1016/j.aquaculture.2008.10.024 (2009).

109. Roberts, S. D. \& Powell, M. D. The viscosity and glycoprotein biochemistry of salmonid mucus varies with species, salinity and the presence of amoebic gill disease. J. Comp. Physiol. B 175, 1-11. https://doi.org/10.1007/s00360-004-0453-1 (2005).

110. Kalujnaia, S. et al. Transcriptomic approach to the study of osmoregulation in the European eel Anguilla anguilla. Physiol. Genomics 31, 385-401. https://doi.org/10.1152/physiolgenomics.00059.2007 (2007).

111. Shaw, J. R. et al. The role of SGK and CFTR in acute adaptation to seawater in Fundulus heteroclitus. Cell Physiol. Biochem. 22, 69-78. https://doi.org/10.1159/000149784 (2008).

112. Kammerer, B. D., Sardella, B. A. \& Kultz, D. Salinity stress results in rapid cell cycle changes of tilapia (Oreochromis mossambicus) gill epithelial cells. J. Exp. Zool. A Ecol. Genet. Physiol. 311, 80-90. https://doi.org/10.1002/jez.498 (2009).

113. Ronkin, D., Seroussi, E., Nitzan, T., Doron-Faigenboim, A. \& Cnaani, A. Intestinal transcriptome analysis revealed differential salinity adaptation between two tilapiine species. Comp. Biochem. Physiol. Part D Genomics Proteomics 13, 35-43. https://doi. org/10.1016/j.cbd.2015.01.003 (2015).

114. Dong, Y. W. et al. Genomic and physiological mechanisms underlying skin plasticity during water to air transition in an amphibious fish. J. Exp. Biol. 224, jeb235515. https://doi.org/10.1242/jeb.235515 (2021). 
115. Inokuchi, M. \& Kaneko, T. Recruitment and degeneration of mitochondrion-rich cells in the gills of Mozambique tilapia Oreochromis mossambicus during adaptation to a hyperosmotic environment. Comp. Biochem. Physiol. A Mol. Integr. Physiol. 162, 245-251. https://doi.org/10.1016/j.cbpa.2012.03.018 (2012).

\section{Acknowledgements}

This study was supported by the King Abdullah University of Science and Technology (KAUST). The project was completed under ethics permit 15IBEC35_Ravasi from the Institutional Biosafety and BioEthics Committee (IBEC) of KAUST. We thank KAUST Coastal and Marine Resources Core Lab and Jessica L. Norstog for assistance with animal collection and maintenance. We also thank KAUST Bioscience Core Lab for assistance with Illumina library preparation and sequencing.

\section{Author contributions}

L.C.B., A.A.M., C.S. conceived, designed and performed the experiment, with input from T.R. L.C.B. and C.S. performed the sample collection. L.C.B. and A.A.M. prepared the samples for RNA sequencing. L.C.B. analyzed the data, with input from C.S. and R.L. L.C.B. interpreted the data and wrote the manuscript, with input from C.S. All authors provided input to and approved the final version of the manuscript.

\section{Competing interests}

The authors declare no competing interests.

\section{Additional information}

Supplementary Information The online version contains supplementary material available at https://doi.org/ 10.1038/s41598-021-97295-3.

Correspondence and requests for materials should be addressed to L.C.B. or C.S.

Reprints and permissions information is available at www.nature.com/reprints.

Publisher's note Springer Nature remains neutral with regard to jurisdictional claims in published maps and institutional affiliations.

(c) (i) Open Access This article is licensed under a Creative Commons Attribution 4.0 International License, which permits use, sharing, adaptation, distribution and reproduction in any medium or format, as long as you give appropriate credit to the original author(s) and the source, provide a link to the Creative Commons licence, and indicate if changes were made. The images or other third party material in this article are included in the article's Creative Commons licence, unless indicated otherwise in a credit line to the material. If material is not included in the article's Creative Commons licence and your intended use is not permitted by statutory regulation or exceeds the permitted use, you will need to obtain permission directly from the copyright holder. To view a copy of this licence, visit http://creativecommons.org/licenses/by/4.0/.

(C) The Author(s) 2021 